\title{
Fabrication Process for an Optomechanical Transducer Platform with Integrated Actuation
}

\author{
Thomas Michels $^{1,2}$, Ivo W. Rangelow ${ }^{2}$, and Vladimir Aksyuk ${ }^{1}$ \\ ${ }^{1}$ Center for Nanoscale Science and Technology, \\ National Institute of Standards and Technology, \\ Gaithersburg, MD 20899 \\ ${ }^{2}$ Ilmenau University of Technology, \\ 98693 Ilmenau, Germany \\ thomas.michels@nist.gov \\ ivo.rangelow@tu-ilmenau.de \\ vladimir.aksyuk@nist.gov
}

\begin{abstract}
This article reports a process for batch fabrication of a fiber pigtailed optomechanical transducer platform with overhanging. The platform enables a new class of high bandwidth, high sensitivity, and highly integrated sensors that are, compact, robust, and small, with the potential potential for low cost batch fabrication inherent in Micro-Opto-Electro-Mechanical-Systems technology. This article provides a guide to the whole fabrication process and explains critical steps and process choices in detail. Possible alternative fabrication techniques and problems are discussed. The fabrication process consists of electron beam lithography, i-line stepper lithography, and back- and frontside mask aligner lithography. The goal of this article is to provide a comprehensive description of the fabrication process, presenting context and details which are highly relevant to the rational implementation and reliable repetition of the process. Moreover, this process makes use of equipment commonly found in nanofabrication facilities and research laboratories, facilitating the broad adaptation and application of the process. Therefore, while this article specifically informs users of the Center for Nanoscale Science and Technology (CNST) at the National Institute of Standards and Technology (NIST), we anticipate that this information will be generally useful for the nano- and microfabrication research communities at large.
\end{abstract}

Key words: AFM; bulk micromachining; optomechanics; surface micromachining.

Accepted: November 22, 2016

Published: December 8, 2016

https://doi.org/10.6028/jres.121.028

\section{Introduction}

The measurement of physical quantities by transducing them to a mechanical motion has a long history. The recent advancements in fabrication of micro- and nanomechanical resonators have continued this trend [1]. Ongoing miniaturization and better process control have enabled high quality factors for both optical and mechanical resonators and therefore more sensitive measurement of microscopic physical phenomena. While micromechanical pressure and acceleration sensors are now ubiquitous in consumer electronics and other products of everyday life, in the physics laboratory micro- and nanoscale resonators allow measurements with an unprecedented degree of precision [2].

One of the most significant obstacles to realizing the full potential of micro- and nanomechanical sensing is the readout of the motion of the small resonator with high sensitivity, high bandwidth, and without excess power dissipation. In the past years numerous methods for the readout of resonator motion 
have been developed [3]. Electrical readout schemes, such as capacitive, magnetomotive, piezoresistive [4], and piezoelectric are convenient but suffer from various combinations of poor scaling with reduced size, power dissipation limitations, magnetic field and material requirements, and thermal Johnson noise in the readout signal. On the other hand, optical readout schemes, such as beam deflection and interferometric, substitute optical shot noise for thermal noise, in principle don't dissipate any power at the transducer, and have a high measurement bandwidth. However, to effectively couple motion to light, most of the off-chip optical methods need a certain minimum moving structure size and reflectivity, which often involves bulky structures or mechanically dissipative reflective coatings.

In nanophotonic optical cavities, the light is trapped in a very small volume and is made to interact for a longer time and more closely with the mechanical resonator. Typical photonic cavity optical quality factors on the order of $10^{5}$ to $10^{6}$ increase the readout signal-to-noise by the same factor. The readout bandwidth is reduced from $\approx 100 \mathrm{THz}$ optical frequency to about $\approx 100 \mathrm{MHz}$, still fast enough for most mechanical sensors. Maintaining stable coupling of a microscopic mechanical resonator with an off-chip optical cavity is challenging due to alignment and drift of components with respect to each other. Here this challenge is overcome by integrating the high quality factor optical cavity directly underneath the moving device, allowing strong interaction with the optical near-field of the cavity, while avoiding mechanical contact (Fig. 1). This interaction is described by the optomechanical coupling coefficient ( $g_{O M}$ typically $\left[\frac{\mathrm{GHz}}{\mathrm{nm}}\right]$ ) relating the change in optical frequency of the micro disk cavity to the displacement of the mechanical device. This fully integrated stable and practical optomechanical transducer is fiber connectorized and implements the readout of mechanical motion with gigahertz bandwidth [5, 6].

Low-loss, stable and robust fiber coupling of the transducer is essential to allow sensitive and reliable operation. Therefore, the fibers have to be securely attached to the chip without the introduction of excess losses between the on-chip waveguide and the optical fiber.

This readout approach allows independent tailoring of the various optical and mechanical parts of the transducer. The photonics can be separately optimized for low losses, high quality factor and desired cavity size, while tuning the waveguide-cavity coupling depth and the optomechanical coupling to achieve the optimal readout sensitivity and dynamic range. Another approach, which uses optical forces to tune the cavity has been presented by . The mechanical components' size, shape, stiffness, and resonance frequency can be tailored to best address the specific sensing applications. The actuation can be tailored for the needed displacement and force ranges, ideally without introducing mechanical losses, avoiding increased mechanical noise and decreased $\mathrm{Q}$ in resonators.

The process reported in this article builds up on a large body of related literature [1,7-15]. The distinguishing characteristic of this article is the comprehensive description, presenting context and details that previous reporting on related topics have not discussed. Many groups are working on optomechanics and the application in transducers [16]. However, most devices focus on specific parts of a transducer, e.g., tuning of optical cavities [17], coupling to optical chips [18-20], displacement measurement on a moveable structures [2, 21-23], or the fundamental physics of optical microdisk cavities [24-26]. This article addresses the challenge of engineering a compact, robust fiber pigtailed optomechanical transducer platform based on this. While this information is highly relevant to users of the equipment at the Center of Nanoscale Science and Technology (CNST) at the National Institute of Standards and Technology (NIST), other nanofabrication facilities and research laboratories have comparable equipment, instruments, and materials. from various commercial vendors, to which this process is potentially adaptable. Therefore, we anticipate that this information will be generally useful for the nanofabrication and nanophotonic research community. The process steps can also be adapted for other fabrication projects.

Figure 1 schematically illustrates the arrangement of the different components in our transducer platform, such as the optical fiber, inverse-taper coupler, waveguides, microdisk cavity, and the mechanical (torsional cantilever) structure. Electrically-controlled actuators (not shown) are also included in the platform to tune the static position and dynamically excite the motion of the mechanical device.

The photonic structures for operation in the telecommunication wavelength range $(\approx 1550 \mathrm{~nm})$ are fabricated in the silicon device layer of a silicon-on-insulator (SOI) wafer, because of the outstanding optical 


\section{Journal of Research of National Institute of Standards and Technology}

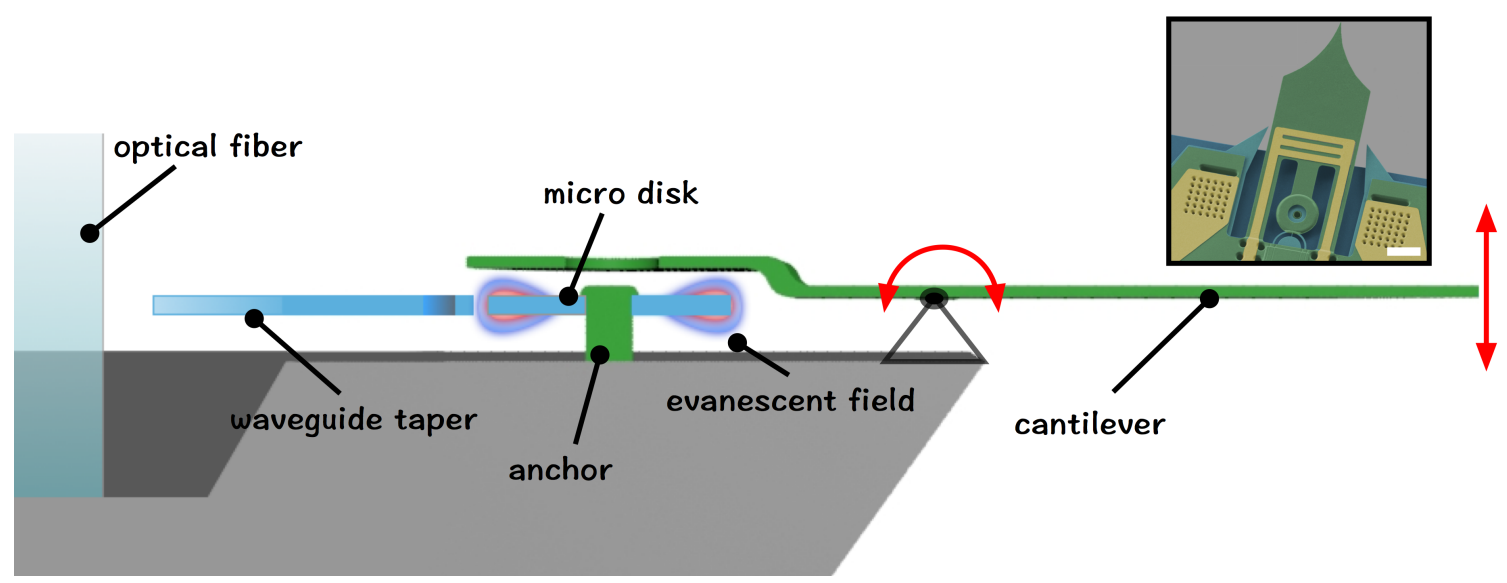

Fig. 1. Exemplary schematic of the transducer (not to scale) showing overhung cantilever on a torsional pivot as the mechanical device. SiN is shown in green, $\mathrm{Si}$ is shown in blue and grey. The red arrow indicates the direction of movement. (inset) False-color scanning electron micrograph of a released device after the fabrication process. Yellow represents metallization, green represents $\mathrm{SiN}$, light blue represents the Si device layer, and dark blue represents the $\mathrm{Si}$ handle wafer. Scale bar is $10 \mu \mathrm{m}$.

and mechanical properties of silicon. The mechanical device is created in silicon nitride $(\mathrm{SiN})$, because it shows good mechanical properties resulting in high quality factor devices, has low optical loss, an index of refraction below that of $\mathrm{Si}$ and is compatible with a hydrofluoric (HF) acid release. For the metallization we choose gold with a chromium adhesion layer $(\mathrm{Cr} / \mathrm{Au})$, compatible with $\mathrm{HF}$ and potassium hydroxide $(\mathrm{KOH})$ etches. Furthermore, the combination of $\mathrm{SiN}$ and $\mathrm{Cr} / \mathrm{Au}$ shows a good thermal bimorph actuation efficiency. Silicon dioxide is used as the sacrificial material.

The sensitivity to motion is proportional to the optical quality factor of the micro disk cavity and quickly increases with decreasing gap between the cavity and the mechanical resonator [1]. It is therefore important to accurately locate the mechanical structure in close proximity to the optical micro disk cavity, while maintaining the high optical quality $\left(\approx 10^{5}\right.$ to $\left.\approx 10^{6}\right)$ factor of the micro disk optical mode. In our design, the micro resonator is lithographically aligned to the disk, and completely encloses it, while a sacrificial layer defines the gap in the fabrication process. A dedicated lithography step and an etch step are used to reduce the sacrificial layer thickness to a predetermined value at the optomechanical transducer $(\approx 400 \mathrm{~nm})$, allowing us to control the gap within tens of nanometers, while keeping a thicker silicon dioxide sacrificial and cladding layer elsewhere. The thickness has been determined with simulations and measurements [7]. It is important that the gap between the silicon microdisk and the silicon nitride is not too small, to avoid excessive leakage form the optical mode into the silicon nitride layer. This would dramatically reduce the optical quality factor of the device. Furthermore, for some of the transducers presented in this paper, discussed in other papers, it is possible to tune the readout gain [5]

Separating photonic and mechanical layers affords flexibility in the design of the mechanical parts to suit specific sensing applications. Within the same process flow, we design and fabricate mechanical cantilever structures, torsional structures, and membranes, on chip structures, and overhanging structures, as well as various types of actuation mechanisms (Fig. 2). The transducer arrays can be used for the simultaneous high sensitivity force detection, such as in parallelized scanning probe microscopy. The membrane transducers show a high mechanical quality factor and good frequency stability, which can be used to study forces acting on samples attached to the membrane. Four different designs of the membrane transducer are designed to have resonance frequencies between $\approx 70 \mathrm{kHz}$ and $\approx 2 \mathrm{MHz}$. The two different option for excitation of the probes allow to design probes with a high quality factor and stable resonance frequency as well as probes with tunable readout gain. The cantilever probes show resonance frequencies 


\section{Journal of Research of National Institute of Standards and Technology}

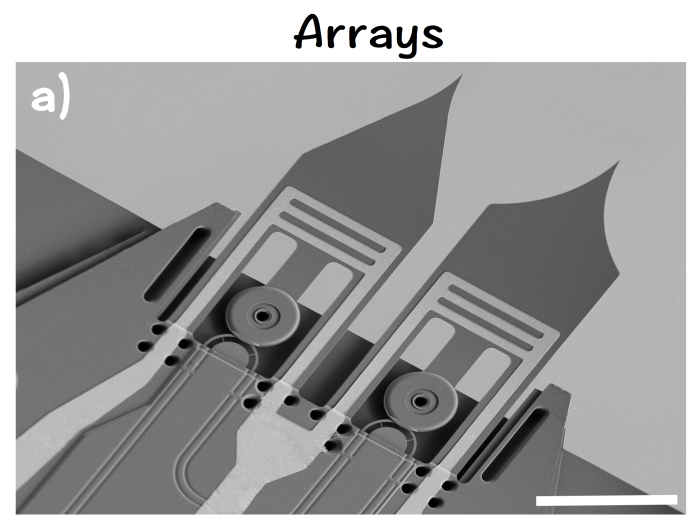

Electrostatic actuation

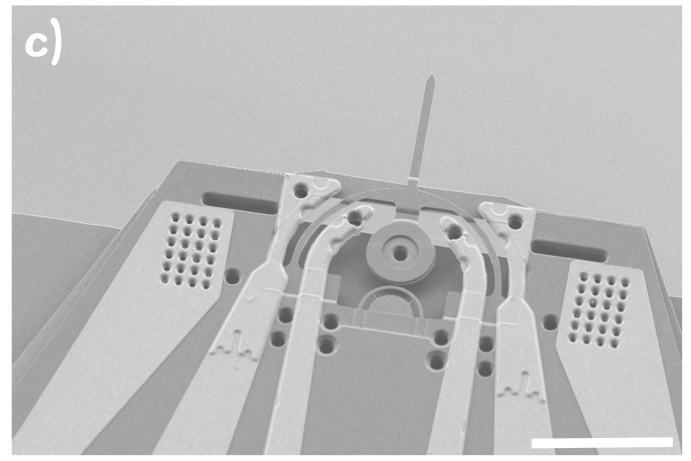

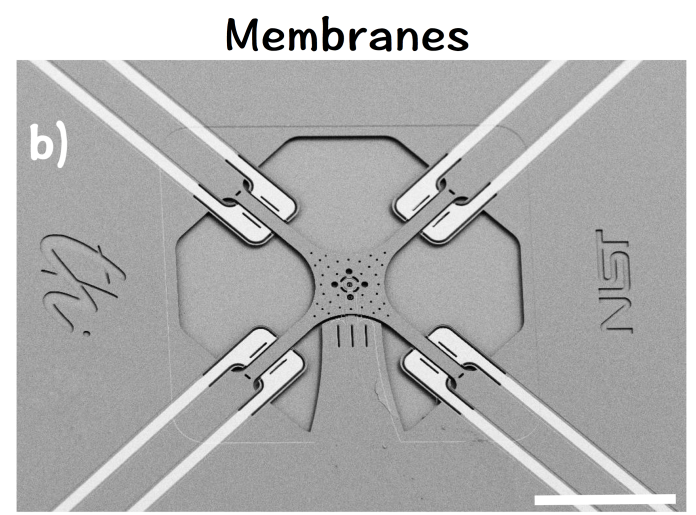

Bimorph actuation

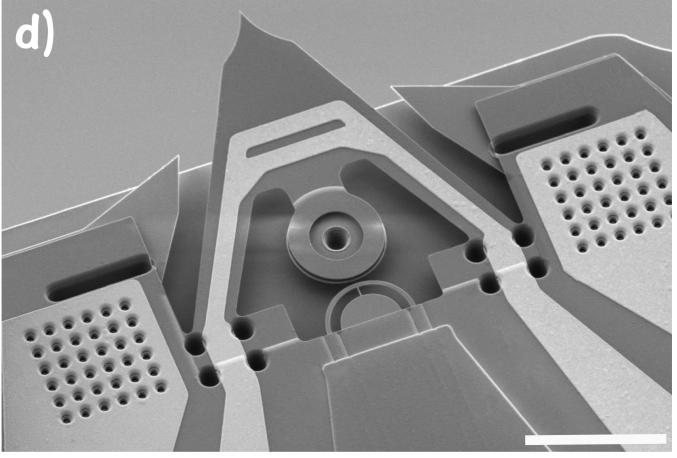

Fig. 2. Designs realized with the described process flow. The scale bars correspond to a) $20 \mu \mathrm{m}$, b) $100 \mu \mathrm{m}$, c) $30 \mu \mathrm{m}$, and d) $30 \mu \mathrm{m}$.

between $\approx 50 \mathrm{kHz}$ and $\approx 2 \mathrm{MHz}$ for the first eigenmode.

The integration of an actuator increases the range of possible applications. The built-in static actuation allows tuning the transducer gain and measurement range. This is accomplished by changing the static gap size between the mechanical structure and the optical cavity. We decided to develop designs for two actuation schemes, thermal bimorph and electrostatic actuation. Bimorph actuators deliver fast responses and large forces. However, the introduction of metal on the mechanical structure creates significant internal losses and therefore reduces the mechanical quality factor. In contrast, electrostatic fringe field actuation doesn't need any metal in contact with the mechanical member, which lets the mechanical member freely oscillate and doesn't affect the mechanical quality factor. This commonly used type of actuation enables measurements on dielectric resonators [27, 28], where useful electrostatic forces for frequency tuning and motion excitation are applied directly to the dielectric structure, thus avoiding any unwanted degradation of the mechanical quality factor.

\section{Overview of the Fabrication Process}

The main challenge is to fabricate these diverse optical, mechanical, and electrical structures in a unified batch fabrication process and a single platform, which can be tailored for specific applications. In the following we will present the process using the overhanging cantilever probe as an example [5].

The fabrication of the cavity optical transducer is based on double-side polished SOI. The process flow is summarized in Fig. 3. In the first step, the waveguide taper, waveguide, and micro disk are defined via electron beam lithography and inductively-coupled reactive ion etching (RIE) of the SOI device layer down 


\section{Journal of Research of National Institute of Standards and Technology}

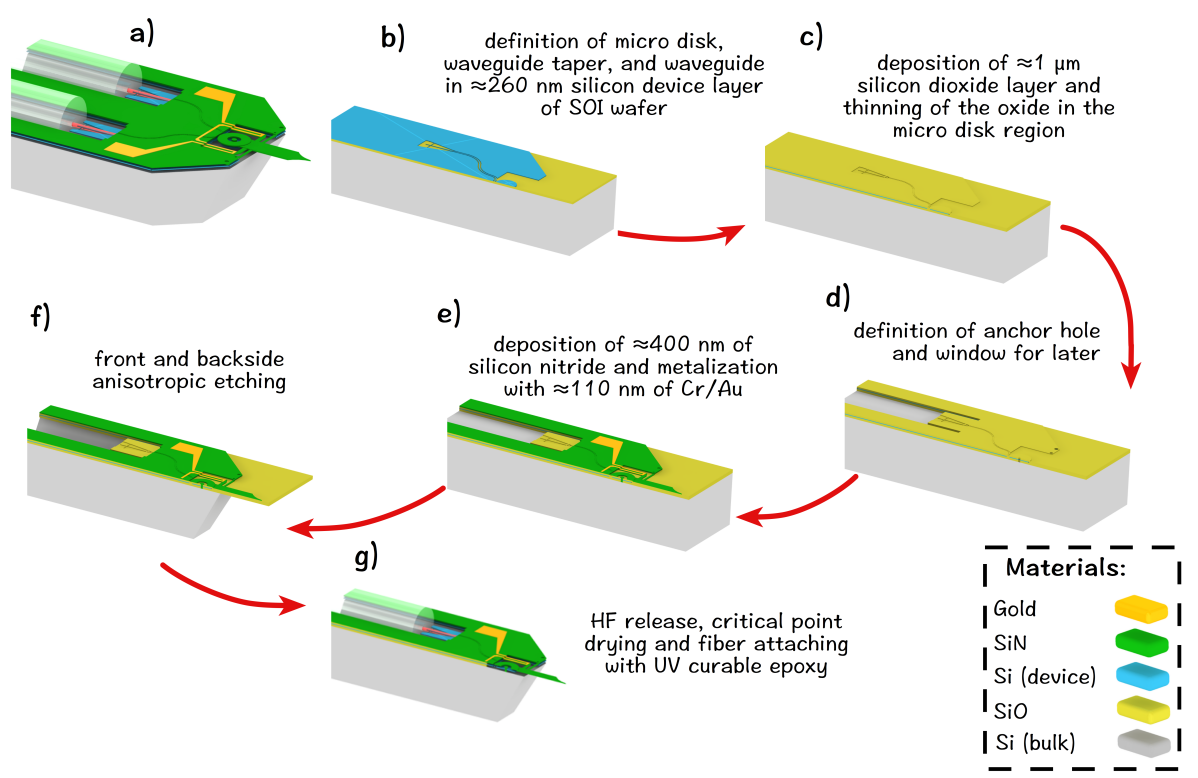

Fig. 3. Representation of the process flow for the transducer with integrated thermal actuation and overhanging tip. The image in the top left shows the finished device (a). (b) Definition of micro disk, waveguide taper, and waveguide in $\approx 260 \mathrm{~nm}$ silicon device layer of SOI wafer. (c) Deposition of $\approx 1 \mu \mathrm{m}$ silicon dioxide layer in micro disk region. (d) Definition of anchor hole and window for later V-groove etching. (e) Deposition of $\approx 400 \mathrm{~nm}$ of silicon nitride and metallization with $\approx 110 \mathrm{~nm}$ of $\mathrm{Cr} / \mathrm{Au}$. (f) Front and backside anisotropic etching. (g) HF release, critical point drying and fiber attaching with UV curable epoxy.

to the buried oxide layer (BOX). The nominal width of the waveguide is $\approx 500 \mathrm{~nm}$ and the gap between the waveguide and the disc is defined to be $\approx 340 \mathrm{~nm}$. Both waveguide ends are linearly tapered down to a width of $\approx 100 \mathrm{~nm}$ over the distance of $\approx 50 \mu \mathrm{m}$ for low loss coupling to/from optical fibers $(\approx 5.5 \mathrm{~dB}$ per facet) (Fig. 3 b) [5]. The remaining structures are defined by i-line stepper optical lithography unless otherwise noted (ASML PAS 5500/275D $\left.{ }^{1}\right)$. A sacrificial silicon dioxide layer $(\approx 1 \mu \mathrm{m})$ is deposited in a low-pressure chemical-vapor deposition furnace (LPCVD) and defined to create a window to the $\mathrm{Si}$ substrate for the later $\mathrm{KOH}$ etching as well as a hole in the center of the micro disk, which is used to anchor the micro disk to the bulk silicon with the following SiN layer. The silicon dioxide is thinned down by a $\mathrm{CF}_{4}$ plasma etch through a lithographically-defined window in photoresist in the region above the micro disk to ensure good optomechanical coupling (Fig. $3 \mathrm{c}, \mathrm{d}$ ). The optomechanical coupling for these devices is $\approx 26 \frac{\mathrm{GHz}}{\mathrm{nm}}$. A low-stress silicon nitride layer $(\approx 400 \mathrm{~nm})$ deposited with LPCVD acts as a passivation layer in the waveguide region and as a structural material for the mechanical structure. Following nitride deposition, a gold layer is deposited and defined in a liftoff process to create a micro heater, electrical connection, and wire bond pads. (For the electrostatically actuated transducer, the micro heater is replaced by electrodes for fringe field actuation). The SiN layer is lithographically patterned (Fig. 3 e), and dry etched to form the SiN cantilever, SiN ring above the micro disk, and SiN anchor to mechanically attach the micro disk to the bulk silicon. The previously defined metal layer is used as a hard mask for SiN, to self-align the SiN structure in critical areas (Fig. 3 e). For front side protection during the later $\mathrm{KOH}$ etch, a hafnium oxide (HfO) layer is deposited with atomic layer deposition. In the following, a RIE is used to open up a window in the $\mathrm{HfO}$ and $\mathrm{SiN}$ for anisotropic etching of the silicon, and to form v-grooves for optical fibers. A back to front aligned backside lithography followed by RIE etching is used to form an anisotropic

\footnotetext{
${ }^{1}$ This article identifies certain commercial equipment, instruments, and materials to specify the experimental procedure. Such identification does not imply recommendations or endorsement by the National Institute of Standards and Technology, nor does it imply that the equipment, instrument, and materials identified are necessarily the best available for the purpose.
} 
etch window on the backside as well. Both lithographies for the definition of the front and back side etch window for anisotropic etching are defined with contact aligner lithography. During the anisotropic silicon etch, V-grooves are formed on the front side of the chip and the shape of the cantilever chip is defined by etching through the handle wafer from the backside (Fig. 3 e). (Another approach is the replacement of the backside $\mathrm{KOH}$ etch with an ICP etch to create a backside trench with vertical sidewalls. This approach is currently being used to develop acceleration sensors with large seismic masses made from the handle wafer.) Silicon dioxide layers and $\mathrm{HfO}$ are removed by $49 \% \mathrm{HF}$ wet etching to undercut and release the movable structures as well as the micro disk, which is anchored to the bulk silicon with a SiN anchor. A critical point drying process is used to avoid stiction between the parts due to capillary forces (Fig. $3 \mathrm{f}$ ). At the end of each v-groove the overhanging waveguide inverse tapers are suspended between silicon support structures and coupled to optical fibers. Which are placed in the V-groove, actively aligned and glued into place with ultraviolet (UV) light curable epoxy.

\section{Detailed Fabrication Process}

In this section we will explain the fabrication process in detail and will provide all information to successfully reproduce the transducers.

The described fabrication process is based on a $100 \mathrm{~mm}$ SOI wafer. The device layer thickness of the wafer is $\approx 260 \mathrm{~nm}$ with low doping to insure good optical transmission [29]. The buried oxide layer has a thickness of $\approx 2 \mu \mathrm{m}$, which is important to prevent leakage of the optical energy in the guided mode from the photonic structure into the silicon handle wafer. The crystal orientation in the handle wafer and the device layer is $\langle 100\rangle$ which results in the desired V-groove and cantilever chip shape after the anisotropic etching.

\subsection{Backside Polishing}

The fabrication starts with polishing the backside of the SOI wafer for better control of the anisotropic backside etching as one of the final fabrication steps. The polishing is achieved with a table-top chemicalmechanicals- polishing system (CMP). For the protection of the front side of the wafer during the polishing process, a combination of a silicon dioxide hard mask and a soft mask created with photoresist is used. The hard mask is created with a flowable oxide (i.e., FOX 16). The flowable oxide is based on an inorganic polymer in a methyl isobutyl ketone (MIBK) carrier solvent, the solvent volatilizes rapidly from the resin, leaving a planar surface. The soft mask consists of a thick photoresist mask.

\subsubsection{Cleaning}

- the wafer is cleaned with N-Methyl-2-pyrrolidone (Resist remover 1165 ) at $\approx 70{ }^{\circ} \mathrm{C}$ for $\approx 15 \mathrm{~min}$

- followed by a rinse with isopropyl alcohol and blow dry with nitrogen gun

- alternatively, the wafer can be dried in the spin dryer, this is especially useful for batch fabrication runs with more then one wafer

\subsubsection{Frontside Protection - Hard Mask}

- "FOX 16 " diluted $\approx 1: 10$ with MIBK is used for the hard mask

- the FOX is applied with the following spin coater setting of $\approx 10.47 \mathrm{rad} / \mathrm{s}(\approx 100 \mathrm{rpm})$ for $\approx 5 \mathrm{~s}$ followed by $\approx 314.16 \mathrm{rad} / \mathrm{s}(\approx 3000 \mathrm{rpm})$ for $\approx 40 \mathrm{~s}$

- the mask is cured in three consecutive soft bake steps to prevent the layer from cracking. Starting with $\approx 90{ }^{\circ} \mathrm{C}$ for $\approx 1 \mathrm{~min}$, followed by $\approx 180{ }^{\circ} \mathrm{C}$ for $\approx 1 \mathrm{~min}$, and $\approx 400{ }^{\circ} \mathrm{C}$ for $\approx 1 \mathrm{~min}$, resulting in a cured thickness of $\approx 400 \mathrm{~nm}$. 


\subsubsection{Frontside Protection - Soft Mask}

- the soft mask is created with a thick photo resist layer ("AZ 10xT") with the following spin coater parameter of $\approx 10.47 \mathrm{rad} / \mathrm{s}(\approx 100 \mathrm{rpm})$ for $\approx 5 \mathrm{~s}$ followed by $\approx 209.44 \mathrm{rad} / \mathrm{s}(\approx 2000 \mathrm{rpm})$ for $\approx 45 \mathrm{~s}$

- the polymer layer is cured in a soft bake step of $\approx 115^{\circ} \mathrm{C}$ for $\approx 10 \mathrm{~min}$, resulting in a cured thickness of $\approx 12 \mu \mathrm{m}$.

\subsubsection{Chemical Mechanical Polishing (CMP)}

- a slurry solution based on colloidal silica ("Ultra-Sol 556") diluted with deionized water in a ratio of $\approx 4: 10$ is used for the polishing process

- the process steps for the conditioning of the system are summarized below

- for the conditioning of the polishing pad, the "Conditioner" is lowered on our CMP system ("Bruker TMT model CP-4"). The conditioning step is used to break in the polishing pad for reproducible results.

\begin{tabular}{ll} 
Step \#1 & \\
\hline Time: & $5 \mathrm{~min}$ \\
Force: & $2.5 \mathrm{~kg}$ \\
Pump \# 1: & $0 \mathrm{ml} / \mathrm{min}($ Slurry $)$ \\
Pump \# 2: & $40 \mathrm{ml} / \mathrm{min}\left(\mathrm{H}_{2} \mathrm{O}\right)$ \\
Pad: & $\approx 4.7 \mathrm{rad} / \mathrm{s} \approx 45 \mathrm{rpm})(\mathrm{CW})$ \\
Wafer: & $0 \mathrm{rad} / \mathrm{s}(0 \mathrm{rpm})$ \\
Slider: & $50 \mathrm{~mm}$ to $70 \mathrm{~mm}\left(5 \mathrm{~min}^{-1}\right)$ \\
Step \#2 & \\
\hline Time: & $5 \mathrm{~min}$ \\
Force: & $2.5 \mathrm{~kg}$ \\
Pump \# 1: & $50 \mathrm{ml} / \mathrm{min}($ Slurry $)$ \\
Pump \# 2: & $0 \mathrm{ml} / \mathrm{min}\left(\mathrm{H}_{2} \mathrm{O}\right)$ \\
Pad: & $\approx 4.7 \mathrm{rad} / \mathrm{s} \approx 45 \mathrm{rpm})(\mathrm{CW})$ \\
Wafer: & $0 \mathrm{rad} / \mathrm{s}(0 \mathrm{rpm})$ \\
Slider: & $50 \mathrm{~mm}$ to $70 \mathrm{~mm}\left(5 \mathrm{~min}^{-1}\right)$
\end{tabular}

- after the conditioning, the "Conditioner" is raised to allow the wafer/polishing pad contact

- the following parameters are chosen to polish the backside of the wafer down to a polished surface (This entire polishing step removes $\approx 20 \mu \mathrm{m}$ of material on the rough wafer backside of a single-side polished wafer)

\begin{tabular}{ll} 
Step \#1 & \\
\hline Time: & $1 \mathrm{~min}$ \\
Wafer: & $100 \mathrm{~mm}$ \\
Force: & $17.236 \mathrm{kN} / \mathrm{m}^{2}$ \\
Pump \# 1: & $20 \mathrm{ml} / \mathrm{min}($ Slurry $)$ \\
Pump \# 2: & $0 \mathrm{ml} / \mathrm{min}\left(\mathrm{H}_{2} \mathrm{O}\right)$ \\
Pad: & $\approx 3.66 \mathrm{rad} / \mathrm{s}(\approx 35 \mathrm{rpm})(\mathrm{CW})$ \\
Wafer: & $\approx 3.14 \mathrm{rad} / \mathrm{s}(\approx 30 \mathrm{rpm})(\mathrm{CCW})$ \\
Slider: & $50 \mathrm{~mm}$ to $70 \mathrm{~mm}\left(10 \mathrm{~min}^{-1}\right)$
\end{tabular}




\section{Journal of Research of National Institute of Standards and Technology}

\begin{tabular}{ll} 
Step \#2 & \\
\hline Time: & $2 \mathrm{~h}+30 \mathrm{~min}$ \\
Wafer: & $100 \mathrm{~mm}$ \\
Force: & $45.642 \mathrm{kN} / \mathrm{m}^{2}$ \\
Pump \# 1: & $20 \mathrm{ml} / \mathrm{min}(\mathrm{Slurry})$ \\
Pump \# 2: & $0 \mathrm{ml} / \mathrm{min}\left(\mathrm{H}_{2} \mathrm{O}\right)$ \\
Pad: & $\approx 3.66 \mathrm{rad} / \mathrm{s}(\approx 35 \mathrm{rpm})(\mathrm{CW})$ \\
Wafer: & $\approx 3.14 \mathrm{rad} / \mathrm{s}(\approx 30 \mathrm{rpm})(\mathrm{CCW})$ \\
Slider: & $50 \mathrm{~mm}$ to $70 \mathrm{~mm}\left(10 \mathrm{~min}{ }^{-1}\right)$ \\
Step \#3 & \\
\hline Time: & $15 \mathrm{~min}$ \\
Wafer: & $100 \mathrm{~mm}$ \\
Force: & $3.447 \mathrm{kN} / \mathrm{m}^{2}$ \\
Pump \# 1: & $0 \mathrm{ml} / \mathrm{min}(\mathrm{Slurry})$ \\
Pump \# 2: & $50 \mathrm{ml} / \mathrm{min}\left(\mathrm{H}_{2} \mathrm{O}\right)$ \\
Pad: & $\approx 3.66 \mathrm{rad} / \mathrm{s}(\approx 35 \mathrm{rpm})(\mathrm{CW})$ \\
Wafer: & $\approx 3.14 \mathrm{rad} / \mathrm{s}(\approx 30 \mathrm{rpm})(\mathrm{CCW})$ \\
Slider: & $50 \mathrm{~mm}$ to $70 \mathrm{~mm}\left(5 \mathrm{~min}{ }^{-1}\right)$
\end{tabular}

- it is very important that the slurry doesn't sit on the wafer for a long time after the polishing finished, because the slurry will attack the surface immediately

- to avoid an attack of the surface, the wafer is rinsed throughly with DI water right after the polishing to remove all slurry residues and dried with nitrogen.

\subsubsection{Cleaning}

- the wafer is cleaned with N-Methyl-2-pyrrolidone (Resist remover 1165 ) at $\approx 70{ }^{\circ} \mathrm{C}$ for $\approx 15 \mathrm{~min}$

- followed by a rinse with isopropyl alcohol and deionized water DI water (DIW) dump rinse

- buffered oxide etch (16\% BOE) is used for the removal of the hard mask. This etch is performed in cycles of $30 \mathrm{~s}$ of etching and a DI water dump rinse until the silicon surface is hydrophobic. This step takes $\approx 1$ min for the described oxide thickness.

- before the start of the patterning processes, the wafer is cleaned using the Radio Corporation of America cleaning (RCA clean) [30]. the following table lists the parameters used

- RCA Clean

\begin{tabular}{ll} 
RCA I & \\
\hline Solution: & $\mathrm{DIW} / \mathrm{NH}_{4} \mathrm{OH} / \mathrm{H}_{2} \mathrm{O}_{2}(50 \mathrm{ml} / 10 \mathrm{ml} / 10 \mathrm{ml})$ \\
Time: & $\approx 10 \mathrm{~min}$ \\
Temperature: & $\approx 75^{\circ} \mathrm{C}$ \\
HF dip & \\
\hline Solution: & $\mathrm{HF} / \mathrm{DIW}(2 \mathrm{ml} / 100 \mathrm{ml})$ \\
Time: & $\approx 30 \mathrm{~s}$ \\
Temperature: & room temperature $(\mathrm{RT})$ \\
RCA II & \\
\hline Solution: & $\mathrm{DIW} / \mathrm{HCl} / \mathrm{H}_{2} \mathrm{O}_{2}(50 \mathrm{ml} / 10 \mathrm{ml} / 10 \mathrm{ml})$ \\
Time: & $\approx 10 \mathrm{~min}$ \\
Temperature: & $\approx 75^{\circ} \mathrm{C}$
\end{tabular}


- for this step, the wafer should be placed in a $100 \mathrm{~mm}$ cassette for the handling

- it is important to add the hydrogen peroxide only a few minutes before the cleaning, otherwise the hydrogen peroxide will be consumed by the bath before the actual cleaning. The hydrogen peroxide for RCA II should not be added earlier then $\approx 7$ min before the bath is used.

- the wafers are dump rinsed between every step.

- after the last cleaning bath, the wafers are dried in the spin dryer.

- a good test during the cleaning is to check the hydrophobicity of the silicon surface after the HF dip. The surface should be hydrophobic, if this is not the case, the HF dip should be repeated.

\subsection{Alignment Marks}

The following step defines alignment marks for the electron beam lithography. We use the flat of the wafer to align the wafer to the electron beam lithography layer to the crystallographic orientation of the silicon wafer. For the alignment of the electron beam lithography, we create alignment marks with a contact mask aligner and a silicon etch on the wafer. We then use these alignment marks to actively align the lithography pattern written by the electron beam system to the crystal orientation of the wafer. The alignment marks are also used for drift check during the electron beam write, to minimize stitching between the write fields. The depth of these alignment marks is very important to create a mark with good contrast in the electron beam tool. The alignment marks are lithographically defined in an i-line stepper lithography.

\subsubsection{Lithography}

- Hexamethyldiloxane is used for the preparation of the wafer surface to improve the adhesion between resist and wafer surface

- the wafer is heated up in a vacuum furnace to $\approx 120^{\circ} \mathrm{C}$

- after a short bake-out $(\approx 20 \mathrm{~min})$, Hexamethyldiloxane vapor is flowed into the chamber for the deposition, followed by a couple of purge cycles to remove the Hexamethyldiloxane from the chamber prior to venting to atmosphere

- a standard positive photoresist is used for this lithography process ("S1813”)

- the resist layer is applied in a spin coating process, with the following spin speed parameters of $\approx 10.47 \mathrm{rad} / \mathrm{s}(\approx 100 \mathrm{rpm})$ for $\approx 5 \mathrm{~s}$ followed by $\approx 418.88 \mathrm{rad} / \mathrm{s}(\approx 4000 \mathrm{rpm})$ for $\approx 45 \mathrm{~s}$ (final resist layer thickness $\approx 800 \mathrm{~nm}$ )

- the resist is soft baked at $\approx 115{ }^{\circ} \mathrm{C}$ for $\approx 1 \mathrm{~min}$

- the wafer is exposed with $140 \mathrm{~mJ} / \mathrm{cm}^{2}$ (I-line $365 \mathrm{~nm}$ ) at $365 \mathrm{~nm}$ with a focus of $0 \mu \mathrm{m}$, numerical aperture of 0.6 , and a sigma of 0.7 in the "annular" illumination mode

- the pattern is developed in "MF 319 " for $\approx 60 \mathrm{~s}$ followed by a DIW rinse and dried with nitrogen

\subsubsection{Pattern Transfer}

- the structure is transferred with a parallel plate reactive ion etcher ("RIE Uniaxis 790")

- the silicon device layer is etched with a sulfur hexafluoride chemistry, followed by an etch based on fluorocarbon chemistry for the silicon oxide layer (the BOX layer of the SOI wafer) 
- the parameters of the etch are summarized below

\begin{tabular}{ll} 
Si etch & \\
\hline Tool: & RIE \#2 (RIE Unaxis 790) \\
Time: & $3 \mathrm{~min}$ \\
Gases: & $\mathrm{SF}_{6} / \mathrm{CF}_{4}$ \\
Flow rates: & $\approx 6 \mathrm{~mL} / \mathrm{min}(\approx 6 \mathrm{sccm}) / \approx 24 \mathrm{~mL} / \mathrm{min}(\approx 24 \mathrm{sccm})$ \\
Pressure: & $\approx 1 \mathrm{~Pa}(8 \mathrm{mTorr})$ \\
RF power: & $\approx 200 \mathrm{~W}$ \\
Ref. RF power: & $\approx 0 \mathrm{~W}$ \\
DC Bias: & $\approx 516 \mathrm{~V}$ \\
Etch rate: & $\approx 100 \mathrm{~nm} / \mathrm{min}$ \\
$\mathrm{SiO}_{2}$ etch & \\
\hline Tool: & $\mathrm{RIE} \# 2(\mathrm{RIE}$ Unaxis 790$)$ \\
Time: & $12 \mathrm{~min}$ \\
Gases: & $\mathrm{O}_{2} / \mathrm{CHF}$ \\
Flow rates: & $5 \mathrm{~mL} / \mathrm{min}(5 \mathrm{sccm}) / 45 \mathrm{~mL} / \mathrm{min}(45 \mathrm{sccm})$ \\
Pressure: & $6.7 \mathrm{~Pa}(50 \mathrm{mTorr})$ \\
RF power: & $200 \mathrm{~W}$ \\
Ref. RF power: & $\approx 0 \mathrm{~W}$ \\
DC Bias: & $\approx 516 \mathrm{~V}$ \\
Etch rate: & $\approx 35 \mathrm{~nm} /$ min
\end{tabular}

- the depth of the final marks have to be more then $750 \mathrm{~nm}$ to be clearly visible in the electron beam lithography system

\subsubsection{Cleaning}

- after the dry etch, the wafer is cleaned in a piranha solution $\left(\mathrm{H}_{2} \mathrm{SO}_{4}: \mathrm{H}_{2} \mathrm{O}_{2}\right)$ to remove the resist as well as the polymers which have been created during the etch process

- a piranha solution with the ratio $\mathrm{H}_{2} \mathrm{SO}_{4}: \mathrm{H}_{2} \mathrm{O}_{2}$ (3:1) is used

- the wafers are placed in the fresh solution for $\approx 10 \mathrm{~min}$

- followed by a dump rinse and spin dry

\subsection{Electron Beam Lithography}

This step defines the photonic structures in the silicon device layer. The nominal width of the final waveguide is $\approx 500 \mathrm{~nm}$ and the gap between the waveguide and the disk is defined to be $\approx 340 \mathrm{~nm}$. The waveguide is linearly tapered down to a width of $\approx 100 \mathrm{~nm}$ over the distance of $\approx 50 \mu \mathrm{m}$ at both waveguide ends for low loss coupling to optical fibers. All dimensions are positively biased by $10 \mathrm{~nm}$ for the electron beam lithography to take dimension change due to oxidation into account. We use the electron beam resist "ZEP 520A" with a base dose of $\approx 460 \mu \mathrm{C}$. The base dose is modulated to compensate proximity effects in the lithography process, which is critical for the disk/waveguide gap as well as for the waveguide taper width. Small variations in these dimensions have a significant effect on the optical device performance. The electron beam lithography is performed on a gaussian beam electron beam system (JOEL 6300-FS) with a write field of $1 \mathrm{~mm}^{2}$. The structures are written with "floating" write fields to optimize the lithography results. "Floating" fields are primarily used to eliminate stitching in critical areas. Floating field pattern fracturing forces the field stitch boundaries to known areas, which are typically chosen to contain straight sections of a waveguide. Additionally, the layout and pattern conversion are optimized to reduce the writing 
time between consecutive fields containing stitched elements. This reduces any drift induced stitching errors. The resist is developed with hexyl acetate at $\approx 0{ }^{\circ} \mathrm{C}$ to improve the contrast [31,32], followed by a transfer step for the generated pattern into the silicon device layer. We transfer the pattern with a hydrogen bromide and chlorine chemistry $\left(\mathrm{HBr} / \mathrm{Cl}_{2}\right)[33,34]$. This etch was chosen as it is known to be a highly anisotropic silicon etch with good control over the sidewall angle. $\mathrm{HBr}$ also produces fewer defects in the surface. Alternatively, we tried a pseudo gas- chopping approach with a plasma chemistry based on octafluorocyclobutane and sulfur hexaflouride $\left(\mathrm{C}_{4} \mathrm{~F}_{8} / \mathrm{SF}_{6}\right)$. The paragraph (3.3.2) will show a quick comparison and will try to explain the decision for the $\mathrm{HBr}$ chemistry. The lithography step combined with the transfer into the silicon device layer is a critical step in this fabrication process, since a small deviation in the created lateral device dimension can have a significant influence on the optical performance of the devices.

\subsubsection{Lithography}

- for the electron beam lithography the resist "ZEP 520A" is used, because of its good selectivity in our silicon etch process (An alternative product is "CSAR62")

- the resist is applied with a spin coater and the following spin speeds of $\approx 10.47 \mathrm{rad} / \mathrm{s}(\approx 100 \mathrm{rpm})$ for $\approx 5 \mathrm{~s}$ followed by $\approx 366.52 \mathrm{rad} / \mathrm{s}(\approx 3500 \mathrm{rpm})$ for $\approx 35 \mathrm{~s}$ (Which results in a final layer thickness of $\approx 400 \mathrm{~nm})$

- the resist is soft baked at $\approx 180{ }^{\circ} \mathrm{C}$ for $\approx 2 \mathrm{~min}$

- to minimize charging effects during the electron beam lithography, a thin charge dissipation layer based on $\approx 15 \mathrm{~nm}$ of aluminum is used. This thin metal layer has a negligible influence on the electron beam resolution but shows a sufficient conductivity to reduce charging of the resist. Furthermore, aluminum can be easily removed with tetramethylammonium hydroxide (TMAH) based developer after the exposure. The aluminum layer is applied via thermal evaporation (The evaporation with a source based on electron beam heating might affect the resist properties due to unwanted exposure to electron beams)

- for the exposure of the prepared wafer, a "JOEL-JBX 6300-FS" electron beam lithography tool is used, with a base dose of $\approx 460 \mu \mathrm{C}$

- after the exposure, the aluminum layer is removed in TMAH based developer ("MF319") for less then $1 \mathrm{~min}$. Shortly after dipping the exposed sample into the developer, the exposed area will appear in the aluminum layer, before the aluminum layer starts to disappear

- the wafer is rinsed with DIW to remove residuals of the developer and dried with nitrogen

- the wafer electron beam resist is developed in hexyl acetate at $\approx 0{ }^{\circ} \mathrm{C}$ to improve the contrast (A cooling plate based on peltier elements is used to achieve a sufficient temperature control)

- the development in cold hexyl acetate takes $\approx 120 \mathrm{~s}$

- the wafer is removed from the developer and dried with nitrogen immediately to remove developer residuals

- alternatively, the wafer can be rinsed with MIBK and isopropyl alcohol (IPA) before dying (However, MIBK can create cracks in "ZEP 520A" with a thickness of more than about $\approx 400 \mathrm{~nm}$ ) 


\subsubsection{Pattern Transfer}

- before the pattern can be transferred into the silicon device layer, the chamber has to be conditioned for the etch chemistry. Depending on the starting conditions, this sometimes takes more time than mentioned in this recipe.

- the conditioning starts with a bare $100 \mathrm{~mm}$ silicon wafer, which is etched for $\approx 20 \mathrm{~min}$. After the etching the wafer surface should be shiny and not dark black. The shiny surface is a good indicator that the chamber is clean and in reasonable condition. A black surface indicates the creation of black silicon on the wafer, which is an indicator that the chamber condition is not ideal.

\begin{tabular}{ll} 
Conditioning & \\
\hline Tool: & Oxford instrument Plasma etcher (Plasmalab System 100) \\
Time: & $\approx 20 \mathrm{~min}$ \\
Substrate: & $\approx 100 \mathrm{~mm}$ silicon wafer \\
Gases: & $\mathrm{HBr} / \mathrm{Cl}_{2}$ \\
Flow rates: & $\approx 10 \mathrm{ml} / \mathrm{min}(\approx 10 \mathrm{sccm}) / \approx 5 \mathrm{ml} / \mathrm{min}(\approx 5 \mathrm{sccm})$ \\
ICP power: & $\approx 700 \mathrm{~W}$ \\
Ref. ICP power: & $\approx 6 \mathrm{~W}$ \\
RF power: & $\approx 60 \mathrm{~W}$ \\
Ref. RF power: & $\approx 1 \mathrm{~W}$ \\
Pressure: & $\approx 2 \mathrm{~Pa}(\approx 15$ mTorr $)$ \\
Temperature: & $\approx 20^{\circ} \mathrm{C}$ \\
Helium backing: & $\approx 2.6 \mathrm{~Pa}(\approx 20$ Torr $)$ \\
DC Bias: & $\approx 155 \mathrm{~V}$
\end{tabular}

- the conditioning with the bare silicon wafer is followed by a silicon wafer with resist pattern. The exposed silicon area of this wafer is approximately the area which will be etched on the process wafer as well. The only difference is, that this is a bare silicon wafer with a resist mask created via stepper lithography, to create waveguide structures for visual inspection of the etch results.

\begin{tabular}{ll} 
Conditioning & \\
\hline Recipe: & Oxford instrument Plasma etcher (Plasmalab System 100) \\
Time: & $\approx 2 \mathrm{~min} 30 \mathrm{~s}$ \\
Substrate: & $\approx 100 \mathrm{~mm}$ silicon wafer with resist mask \\
Gases: & $\mathrm{HBr} / \mathrm{Cl}_{2}$ \\
Flow rates: & $\approx 10 \mathrm{ml} / \mathrm{min}(\approx 10 \mathrm{sccm}) / \approx 5 \mathrm{ml} / \mathrm{min}(\approx 5 \mathrm{sccm})$ \\
ICP power: & $\approx 700 \mathrm{~W}$ \\
Ref. ICP power: & $\approx 6 \mathrm{~W}$ \\
RF power: & $\approx 60 \mathrm{~W}$ \\
Ref. RF power: & $\approx 1 \mathrm{~W}$ \\
Pressure: & $\approx 2 \mathrm{~Pa}(\approx 15$ mTorr $)$ \\
Temperature: & $\approx 20^{\circ} \mathrm{C}$ \\
Helium backing: & $\approx 2.6 \mathrm{~Pa}(\approx 20$ Torr $)$ \\
DC Bias: & $\approx 142 \mathrm{~V}$
\end{tabular}

- the etch results are inspected in the scanning electron microscope to determine the sidewall angle, etch rate, and uniformity across the wafer. Typical sidewall angles are between $\approx 90^{\circ}$ and $\approx 87^{\circ}$, the 
typical etch rate is $\approx 95 \mathrm{~nm} / \mathrm{min}$ with a etch rate uniformity of $\pm 5 \mathrm{~nm}$ in lateral dimension. The sidewall angle can be adjusted with the process pressure. The test etch is repeated until the desired etch profile is reached.

\begin{tabular}{ll} 
Pattern transfer & \\
\hline Recipe: & Oxford instrument Plasma etcher (Plasmalab System 100) \\
Time: & adjusted with results from test etch \\
Substrate: & $\approx 100 \mathrm{~mm}$ SOI wafer with ZEP 520A \\
Gases: & $\mathrm{HBr} / \mathrm{Cl}_{2}$ \\
Flow rates: & $\approx 10 \mathrm{ml} / \mathrm{min}(\approx 10 \mathrm{sccm}) / \approx 5 \mathrm{ml} / \mathrm{min}(\approx 5 \mathrm{sccm})$ \\
ICP power: & $\approx 700 \mathrm{~W}$ \\
Ref. ICP power: & $\approx 6 \mathrm{~W}$ \\
RF power: & $\approx 60 \mathrm{~W}$ \\
Ref. RF power: & $\approx 1 \mathrm{~W}$ \\
Pressure: & $\approx 2 \mathrm{~Pa}(\approx 15$ mTorr $)$ \\
Temperature: & $\approx 20^{\circ} \mathrm{C}$ \\
Helium backing: & $\approx 2.6 \mathrm{~Pa}(\approx 20$ Torr $)$ \\
DC Bias: & $\approx 142 \mathrm{~V}$
\end{tabular}

- the structure is over etched to create vertical sidewalls across the whole wafer und compensate for possible non uniformities in the vertical etch rate. The displayed DC Bias will change if the surface of the buried oxide layer is reached. The etch rate of the resist is $\approx 72 \mathrm{~nm} / \mathrm{min}$. An overetch into the BOX layer is acceptable as the etch rate on silicon oxide is $\approx 50$ times higher than that of silicon.

\section{Comparison of Silicon etches}

Another commonly used etch chemistry for photonic structures is an ICP etch based on sulfur hexafluoride and octafluorocyclobutane [35]. In contrast to the standard gas chopping process, where these gases are used in alternating steps of "etching" (sulfur hexafluoride) and "passivation" (octafluorocyclobutane), they are used simultaneously instead to create very smooth sidewalls. However, this simultaneous etching and passivation makes the process difficult to use because of a small process window for a stable etch. The rate at which the passivation is deposited on the side wall and bottom of the trench strongly depends on the chamber conditions, i.e., polymers build-up on the chamber walls. We were able to realize devices with similar optical quality factors with this etch chemistry. However, the process strongly depends on the etch load and the chamber conditions and therefore has to be adjusted for every sample. This makes this etch preparation very time consuming. Furthermore, this etch is very sensitive to over etching. During an over-etch, BOX layer will charge up, which creates a deflection of the ions at the bottom. These defected ions etch the sidewall passivation and create notching.

In contrast to this, an over-etch with the $\mathrm{HBr}$ chemistry does not create notching, because the anisotropic properties of the etch are not created by a side wall passivation [36]. The vertical side walls depend on the directional kinetic energy of the $\mathrm{HBr}$ radicals. The etch is based on the amporphization effect of $\mathrm{Cl}_{2}$ and $\mathrm{HBr}$ on silicon.

\subsubsection{Cleaning}

- the wafer is cleaned with a combination of solvents to remove the plasma baked resist after the etching

- in the first step, a solvent based on N-Methylpyrrolidone and N-(2-Hydroxyethyl)-2-Pyrrolidone ("EKC-Remover") at $\approx 70^{\circ} \mathrm{C}$ for $\approx 10 \mathrm{~min}$ 


\section{Journal of Research of National Institute of Standards and Technology}

- followed by a dump rinse and spin dry

- piranha solution $\left(\mathrm{H}_{2} \mathrm{SO}_{2}: \mathrm{H}_{2} \mathrm{O}_{2}\right)$ is used to remove the bulk polymer in a ratio of $\mathrm{H}_{2} \mathrm{SO}_{2}: \mathrm{H}_{2} \mathrm{O}_{2}(3: 1)$ for $\approx 10 \mathrm{~min}$

- followed by a dump rinse and spin dry

\subsection{Silicon Device Layer Pattern}

The electron beam lithography is followed by an i-line stepper lithography to define larger-area structures in the silicon device layer. This step defines a trench around the cantilever chip and removes the silicon device layer below the future cantilever structure. The stepper lithography uses a standard positive photoresist and is followed by an inductive plasma etch process to transfer the structure into the silicon. The $\mathrm{HBr}$ chemistry has been chosen for this step because of the high etch selectivity between silicon and silicon dioxide. The stepper lithography and the earlier electron beam lithography overlap in certain areas to create continuous regions with removed silicon. The high etch selectivity reduces the step between the two areas, which is created in the this etch process.

\subsubsection{Lithography}

- the wafer is prepared as described in Sec. 3.2.1

- the wafer is exposed with $140 \mathrm{~mJ} / \mathrm{cm}^{2}$, a focus of $0 \mu \mathrm{m}$, a numerical aperture of 0.6 , and a sigma of 0.7 in the "angular" illumination mode

- the pattern is developed in "MF 319" for $\approx 60$ s followed by a DIW rinse and dried with nitrogen

\subsubsection{Pattern Transfer}

- the pattern is transferred with the $\mathrm{HBr}$ recipe used earlier (3.3.2)

$\begin{array}{ll}\text { Pattern transfer } & \\ \text { Recipe: } & \text { Oxford instrument Plasma etcher (Plasmalab System 100) } \\ \text { Time: } & \text { adjusted with results from test etch } \\ \text { Substrate: } & \approx 100 \mathrm{~mm} \text { SOI wafer with resist mask } \\ \text { Gases: } & \mathrm{HBr} / \mathrm{Cl}_{2} \\ \text { Flow rates: } & \approx 10 \mathrm{ml} / \mathrm{min}(\approx 10 \mathrm{sccm}) / \approx 5 \mathrm{ml} / \mathrm{min}(\approx 5 \mathrm{sccm}) \\ \text { ICP power: } & \approx 700 \mathrm{~W} \\ \text { Ref. ICP power: } & \approx 6 \mathrm{~W} \\ \text { RF power: } & \approx 60 \mathrm{~W} \\ \text { Ref. RF power: } & \approx 1 \mathrm{~W} \\ \text { Pressure: } & \approx 2 \mathrm{~Pa}(\approx 15 \text { mTorr }) \\ \text { Temperature: } & \approx 20^{\circ} \mathrm{C} \\ \text { Helium backing: } & \approx 2.6 \mathrm{~Pa}(\approx 20 \text { Torr }) \\ \text { DC Bias: } & \approx 142 \mathrm{~V}\end{array}$

- the structure is over etched by $10 \%$ to ensure uniform results 


\subsubsection{Cleaning}

- the wafer is cleaned with piranha solution $\left(\mathrm{H}_{2} \mathrm{SO}_{2}: \mathrm{H}_{2} \mathrm{O}_{2}\right)$ to remove the bulk polymer as well as etch residuals. A ratio of $\mathrm{H}_{2} \mathrm{SO}_{2}: \mathrm{H}_{2} \mathrm{O}_{2}$ (3:1) is used for $\approx 10 \mathrm{~min}$.

- followed by a dump rinse and spin dry

\subsection{Waveguide Cladding and Spacer Layer}

The waveguide cladding layer consists of silicon dioxide. The cladding is created in a thermal oxidation and a chemical vapor deposition (CVD) step where low temperature oxide (LTO) is deposited. A first thermal oxidation step is used to clean the silicon surface from any contamination, as well as defects created during the silicon etch. This clean will also remove the halogenated and amphorizied surface layer, which has been created by $\mathrm{Cl}_{2}$ and $\mathrm{HBr}$ during the silicon etch. The created oxide is removed with a wet oxide etch followed by a second thermal oxidation. The second thermal oxidation creates a good interface layer between the silicon crystal and the silicon dioxide layer created by CVD. Unfortunately, the thickness of the oxide layer created by our deposition tool has a non-unformity of $\approx \pm 10 \%$. To reduce the influence on the deposited layer, the deposition process is spit into three separate depositions. The wafer is turned between the depositions by $\approx 120^{\circ}$. After the first LTO deposition, the layer is etched back with a silicon dioxide dry etch to prevent the creation of encapsulated cavities in the oxide due to the growth dynamics of the CVD process. The dry etch is based on a tetraflourmethane $\left(\mathrm{CF}_{4}\right)$ chemistry, because this chemistry creates fewer etch residuals. This is important to avoid any contaminations of the cladding layer. This step is followed by two LTO depositions and a high temperature anneal in a nitrogen atmosphere. The annealing process drives the hydrogen out of the layer and improves the mechanical, electrical, optical, and chemical (etch rate) properties. The $\mathrm{N}_{2}$ atmosphere is very important to prevent a further oxidation of the silicon device layer.

\subsubsection{Cleaning}

- before the deposition of the cladding layer, the wafer is cleaned with a RCA clean. The wafer is cleaned as described in Sec. 3.1.5

\subsubsection{Thermal Oxidation}

- the SOI wafer is placed with one clean bare monitor silicon wafer on each side in the furnace boat. The monitor wafers are used to determine the grown silicon dioxide thickness after the run.

- the wafers are dry oxidized at $\approx 1000{ }^{\circ} \mathrm{C}$ for $\approx 10 \mathrm{~min}$, which will create an oxide thickness of $\approx 12 \mathrm{~nm}$. Therefore, the original silicon surface is moved $\approx 5 \mathrm{~nm}$ into the silicon, since the volume of thermal oxide consists out of $\approx 44 \%$ silicon.

- the wafers are removed from the furnace and the oxide is stripped in diluted HF $(\approx 2 \%)$, followed by a dump rinse and spin dry. The wafer is etched in diluted HF until the surface is hydrophobic.

- the thermal oxidation is repeated once with the same parameters

\subsubsection{LTO Deposition}

- for the CVD deposition, it is important to determine the deposition rate with a full wafer boat and only on the wafers in the center of the boat. The non-uniformity in this process between wafers can be significant. The wafers in the center are in general more uniform then wafers on the sides of the boat.

- the SOI wafer is placed in the center of the boat with one clean monitor silicon wafer on each side. The monitor wafers are used to determine the grown silicon dioxide thickness after the run. 
- the deposition is performed at $\approx 400{ }^{\circ} \mathrm{C}$ for $\approx 400 \mathrm{~nm}$

- the wafers are removed and etched in a parallel plate reactive ion etcher, the parameter are summarized below:

\begin{tabular}{ll} 
Etch back & \\
\hline Tool: & RIE Unaxis 790 \\
Depth: & $\approx 200 \mathrm{~nm}$ \\
Gases: & $\mathrm{O}_{2} / \mathrm{CF}_{4}$ \\
Flow rates: & $\approx 5 \mathrm{sccm} / \approx 25 \mathrm{sccm}$ \\
Pressure: & $\approx 6.7 \mathrm{~Pa}(\approx 50 \mathrm{mTorr})$ \\
RF power: & $\approx 200 \mathrm{~W}$
\end{tabular}

- after the etch back, the wafers are loaded into the CVD furnace for the next LTO deposition.

- the deposition is again performed at $\approx 400{ }^{\circ} \mathrm{C}$ for $\approx 400 \mathrm{~nm}$

- the wafers are rotated to improve the uniformity of the deposition, followed by the last deposition

- the deposition is performed at $\approx 400{ }^{\circ} \mathrm{C}$ for $\approx 600 \mathrm{~nm}$

- after the final deposition, the wafers should have a final silicon dioxide thickness of $\approx 1.2 \mu \mathrm{m}$

- to finish up the LTO deposition, the wafers are annealed at $\approx 1000{ }^{\circ} \mathrm{C}$ in a $\mathrm{N}_{2}$ atmosphere for $\approx 1 \mathrm{~h}$. The annealing process drives the hydrogen out of the layer and improves the mechanical, electrical, optical, and chemical (etch rate) properties. The $\mathrm{N}_{2}$ atmosphere is very important to prevent a further oxidation of the silicon device layer.

\subsubsection{An Alternative Approach to Create the Cladding}

An alternative approach to create the waveguide cladding layer is FOX [37], used earlier for the polishing hard mask. The advantage of FOX is the outstanding planarization capability, which will level all topographical steps and therefore simplify the lithographies for the following fabrication steps. In addition, the processing time for FOX compared to the LTO deposition is lower and less expensive.

FOX is applied in a spin coating process and soft baked on a hot plate, followed by a rapid thermal annealing (RTA) and a $1 \mathrm{~h}$ annealing in a nitrogen atmosphere.

However, we observed problems with FOX as waveguide cladding for this process. The silicon waveguide is defined by a trench, with an aspect ratio of $(1: 2)$, on each side. In test experiments we cured the FOX layer with different temperatures and atmospheres and were able to create a planar layer without any visible defects or cracks. However, if we released test chips with trench structures in HF, we observed a much higher lateral etch rate for the oxide in the trench compared to the oxide elsewhere. To rule out any effects originating form the interface between the silicon and the oxide cladding we introduced a thin silicon dioxide layer (created with LTO) as interface layer. Figure 4 shows the cleaved cross section of the test structure before (left) and after the HF etch (right). The red circle \#1 points out that there is still LTO left in the corners of the tench, which shows that the lateral etch rate of the LTO is lower compared to the lateral etch rate of FOX in the tench. However, circle \#2 shows that the lateral etch rates for both layers (LTO and FOX) are comparable outside the trench. This suggests that the high internal stress of the FOX layer in the trench has an influence on the lateral etch rate. Since no defects are visible in the optical microscope and scanning electron microscope, we assume that the stress creates nanometer size cracks along the trench which allow a significant increase of the etch rate in HF along the trench. Figure 5 shows a top view of an etch SOI wafer with trench structure, LTO, FOX, and SiN. The difference in the etch rates is clearly visible. We can see an etch rate of $160 \mathrm{~nm} \mathrm{~min}{ }^{-1}$ on the planar surface and $4800 \mathrm{~nm} \mathrm{~min}^{-1}$ in the trench. 


\section{Journal of Research of National Institute of Standards and Technology}

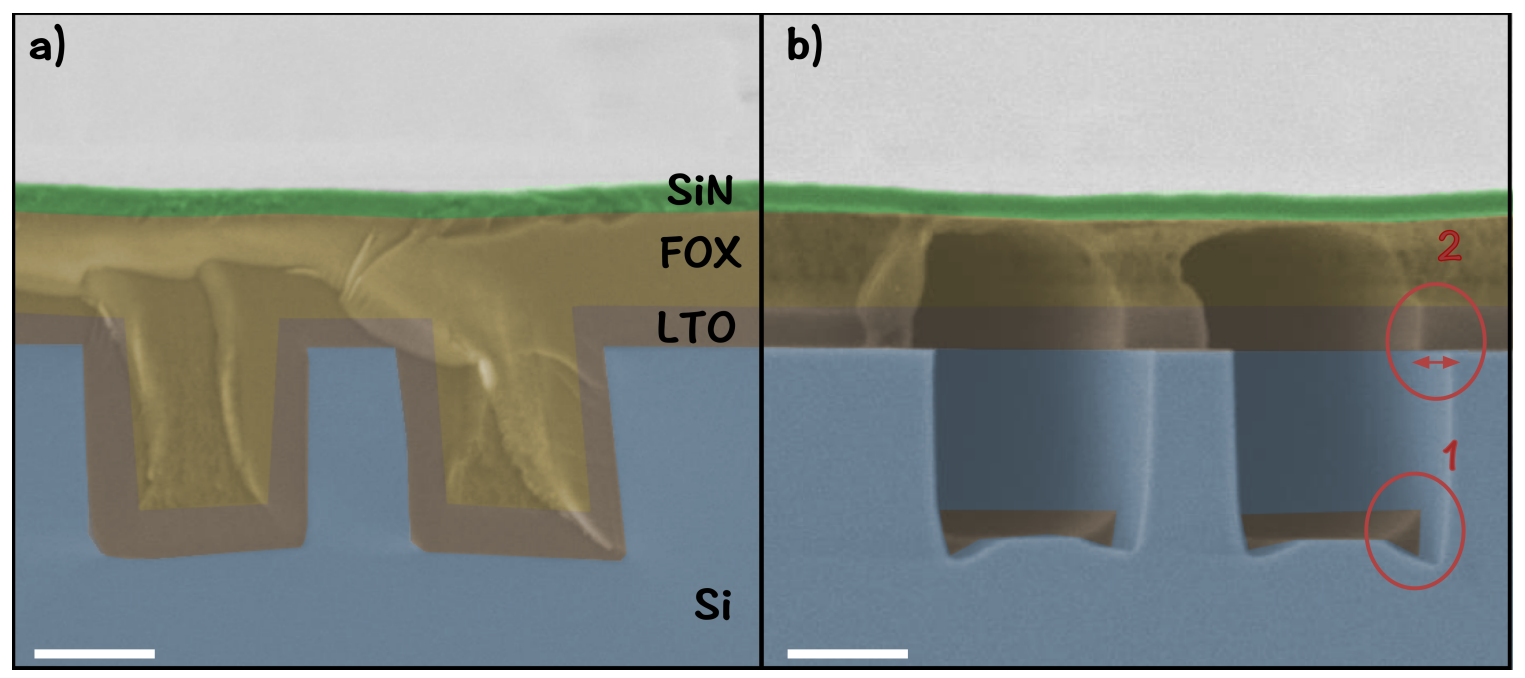

Fig. 4. Cross sectional view of a test sample before (a) and after (b) the exposure to HF. The red circle in \#1 points out that there is still LTO left in the corners of the tench, which shows that the lateral etch rate of the LTO is lower compared to the lateral etch rate of FOX in the tench. However, circle \#2 shows that the lateral etch rates for both layers (LTO and FOX) are comparable outside the trench. This clearly indicates that the high internal stress of the FOX layer in the trench has an influence on the lateral etch rate. The scale bars correspond to $400 \mu \mathrm{m}$.

Another indicator for nanometer size cracks along the trench was found in a second etch experiment with BOE. BOE is known to attack silicon dioxide, but due to a different surface tension it doesn't creep into narrow cracks. The second etch experiment shows a significantly smaller difference between the lateral etch rate in the trench and on planar surface.

\subsection{Definition of the Optomechanical Coupling Region and Anchor Point}

The definition of the gap between the silicon micro disk and the mechanical member (i.e., cantilever or membrane) is important for the optical performance of the transducer. For smaller gaps the optomechanical coupling increases exponentially. However, a smaller gap also decreases the optical quality factor of the disk due to increased loss of optical energy from the disk mode into the silicon nitride structure. Simulations show that a reasonable value for the gap is $\approx 400 \mathrm{~nm}$. Therefore, to reach this value the cladding layer on top of the micro disk has to be thinned down to $\approx 400 \mathrm{~nm}$. Furthermore, an anchor point is created to hold the photonic structures in place after the final removal of the silicon dioxide sacrificial layer. To improve the future anchor point of the micro disk and the transition, between the area with the thick LTO cladding and a thinner LTO layer on top of the disk, a combination of dry etching and wet oxide etching is used. The dry etch creates a step profile in the oxide and the wet etch is used to round the corners of this step profile as well as undercut the silicon micro disk around the future anchor point. Figure 6 shows these process steps in detail.

\subsubsection{Lithography - Thinned Region}

- a bottom antireflective coating (ARC) is used to decouple the optical properties of the sample from the lithography process. The correct thickness of this layer is essential for its functionality. A standard ARC used for this process is "AZ BARLi-II" with a final thickness of $\approx 180 \mathrm{~nm}$. This is achieved with the spin coat parameter summarized below.

- the ARC is followed by a layer of positive photo resist ("SPR 220-3"). 


\section{Journal of Research of National Institute of Standards and Technology}

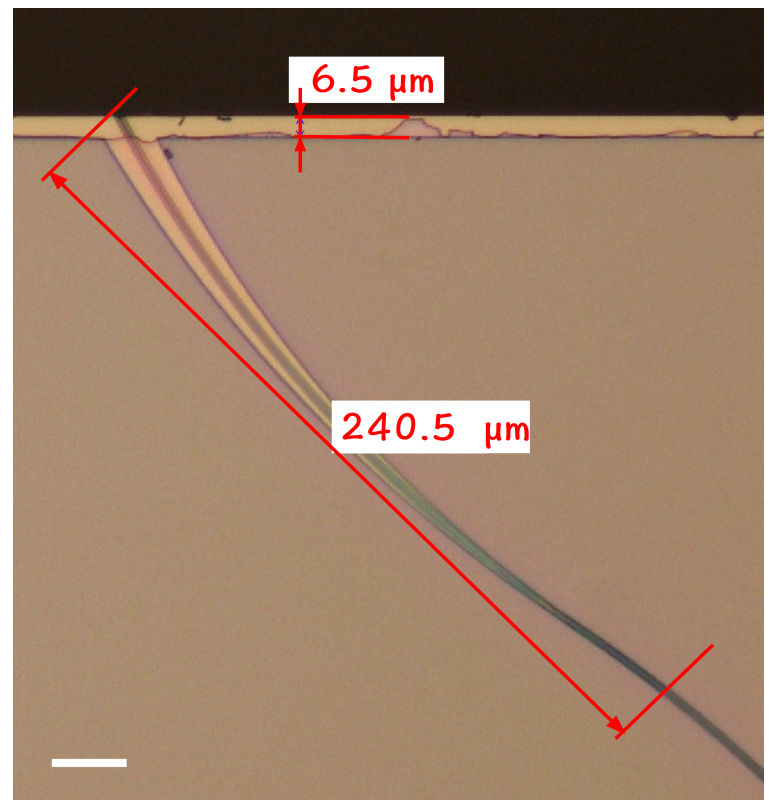

Fig. 5. Top view of a cleaved test sample after the sample was exposed to HF for several minutes. The test sample consists of an SOI wafer structured with a waveguide. The waveguide structure is covered with a layer of LTO, FOX, and SiN. The images shows the difference between the lateral etch rate of the LTO/FOX stack on the planar surface and in the trench aside the waveguide. The scale bars correspond to $30 \mu \mathrm{m}$.

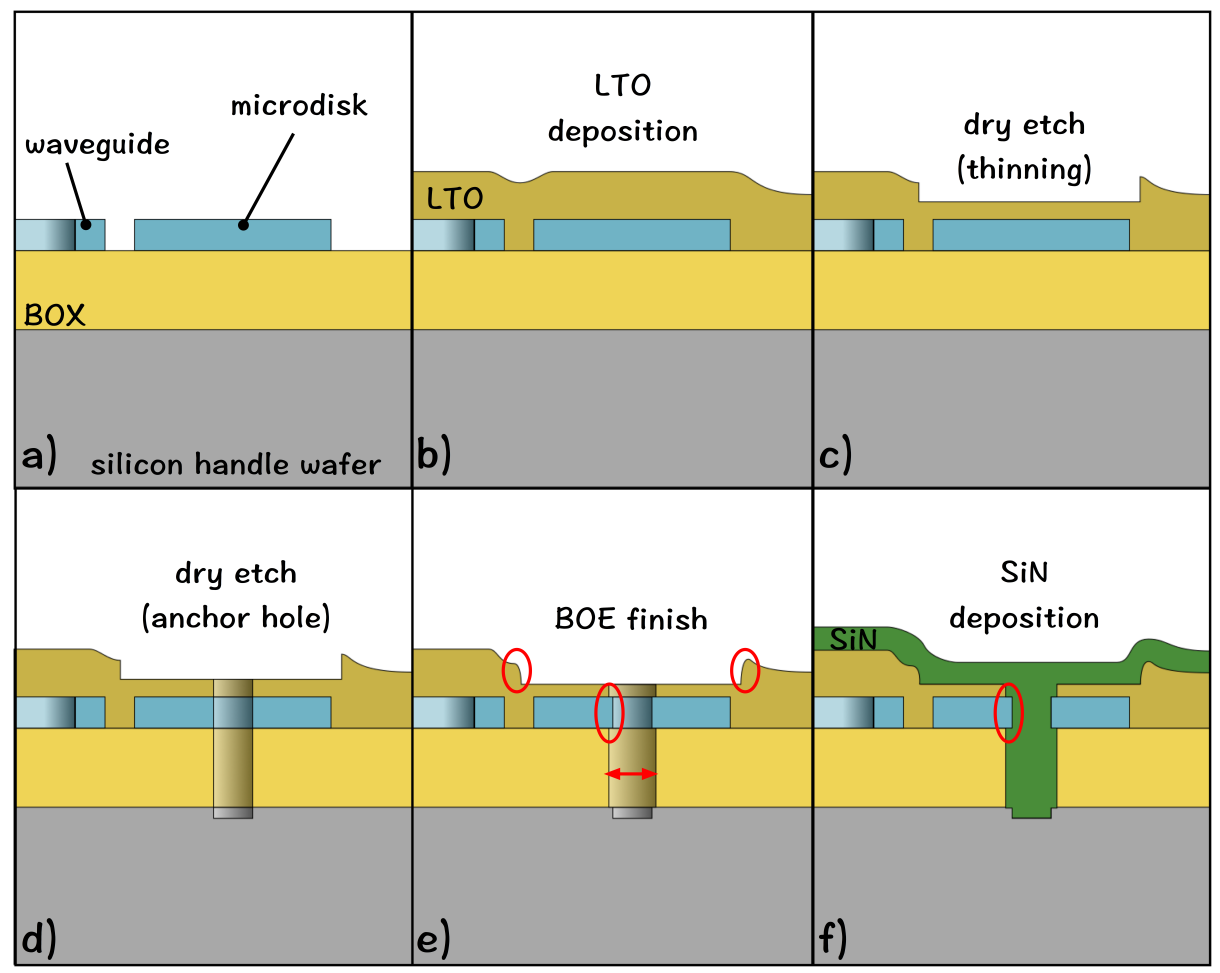

Fig. 6. Representation of selected process steps: a) after the transfer of the photonic structure, b) formation of the cladding layer, c) dry etch step of the thinning process, d) dry etch of the anchor hole, e) BOE finishing of the coupling region and shaping of the anchor hole, and f) SiN deposition. 


\section{Journal of Research of National Institute of Standards and Technology}

- a resist thickness of $\approx 1.2 \mu \mathrm{m}$ has been chosen, because it supplies enough resist for the etch processes as well as good coverage of all topographical steps. The process parameters are summarized below:

Resist

Resist layer 1: BARLi II

Spin speed: $\quad \approx 10.5 \mathrm{rad} / \mathrm{s}(\approx 100 \mathrm{rpm})$ for $\approx 5 \mathrm{~s} / \approx 209.4 \mathrm{rad} / \mathrm{s}(\approx 2000 \mathrm{rpm})$ for $\approx 40 \mathrm{~s}$

Soft bake:

$\approx 200^{\circ} \mathrm{C}$ for $\approx 60 \mathrm{~s}$

Resist layer 2: SPR 220-3

Spin speed:

$\approx 10.5 \mathrm{rad} / \mathrm{s}(\approx 100 \mathrm{rpm})$ for $\approx 5 \mathrm{~s} / \approx 314.2 \mathrm{rad} / \mathrm{s}(\approx 3000 \mathrm{rpm})$ for $\approx 40 \mathrm{~s}$

Soft bake:

$\approx 115^{\circ} \mathrm{C}$ for $\approx 90 \mathrm{~s}$

- the wafer is exposed with $190 \mathrm{~mJ} / \mathrm{cm}^{2}$, a focus of $0.4 \mu \mathrm{m}$, a numerical aperture of 0.48 , and a sigma of 0.5 in the "conventional" illumination mode

- the resist is treated with a post exposure bake, of $\approx 110{ }^{\circ} \mathrm{C}$ for $\approx 60 \mathrm{~s}$, to improve the result of the lithography process.

- in the following, the structure is developed in "AZ $300 \mathrm{MIF}$ " for $\approx 60 \mathrm{~s}$ followed by a DIW rinse and dried with nitrogen

\subsubsection{Pattern Transfer}

- the transfer process starts with a long descum to remove the ARC at the bottom of the lithographically defined structures

- the used oxygen plasma etch only removes the organic part of the ARC; the inorganic part will be removed in the following etch based on tetraflourmethane chemistry

- the etch step with tetraflourmethane chemistry is also used to thin the oxide cladding layer in the region above the disk to a final thickness of $\approx 600 \mathrm{~nm}$ (Fig. $6 \mathrm{c}$ ))

- the process parameters are summarized in the table below, the etch is performed in a parallel pate reactive ion etcher:

\begin{tabular}{ll} 
Descum & \\
\hline Tool: & RIE Unaxis 790 \\
Time: & $\approx 7 \mathrm{~min}$ \\
Gases: & $\mathrm{O}_{2} / \mathrm{Ar}$ \\
Flow rates: & $\approx 5 \mathrm{ml} / \mathrm{min}(\approx 5 \mathrm{sccm}) / \approx 20 \mathrm{ml} / \mathrm{min}(\approx 20 \mathrm{sccm})$ \\
Pressure: & $\approx 4 \mathrm{~Pa}(\approx 30 \mathrm{mTorr})$ \\
RF power: & $\approx 50 \mathrm{~W}$ \\
Ref. RF power: & $\approx 0 \mathrm{~W}$ \\
& \\
$\mathrm{SiO}_{2}$ & \\
\hline Depth: & until a final cladding thickness \\
& of $\approx 600 \mathrm{~nm}$ above the silicon disk is reached \\
Gases: & $\mathrm{O}_{2} / \mathrm{CF} 4$ \\
Flow rates: & $\approx 5 \mathrm{ml} / \mathrm{min}(\approx 5 \mathrm{sccm}) / \approx 25 \mathrm{ml} / \mathrm{min}(\approx 25 \mathrm{sccm})$ \\
Pressure: & $\approx 6.7 \mathrm{~Pa}(\approx 50$ mTorr $)$ \\
RF power: & $\approx 200 \mathrm{~W}$
\end{tabular}




\subsubsection{Cleaning}

- the wafers is cleaned with a combination of solvents and acids to remove the plasma baked resist after the etching as well as the ARC

- the first step of the cleaning is a solution based on N-Methyl-2-pyrrolidone (Resist remover 1165) at $\approx 70{ }^{\circ} \mathrm{C}$ for $\approx 15$ min finished with a dump rinse

- the next step is an acid clean with piranha solution $\left(\mathrm{H}_{2} \mathrm{SO}_{4}: \mathrm{H}_{2} \mathrm{O}_{2}\right)$. The solution is used in a ratio of $\mathrm{H}_{2} \mathrm{SO}_{4}: \mathrm{H}_{2} \mathrm{O}_{2}$ (3:1) for $\approx 10$ min, followed by a dump rinse

- the last step is a solvent clean to remove the inorganic residuals of the ARC. The piranha solution can only remove the organic structure of the ARC but leaves the inorganic backbone of the resist on the surface. The recommended stripper for "AZ BARLi-II" is "AZ 300T stripper", which is used at $\approx 80^{\circ} \mathrm{C}$ for $\approx 10 \mathrm{~min}$, followed by a dry rinse and spin dry

\subsubsection{Lithography - Anchor Holes}

- this lithography defines anchor holes, which go all the way down to the silicon handle wafer, to hold the released photonic structures in place. This requires a long etch process, which requires a UV cross linked resist to improve the resist performance during the etch.

- the first layer is an ARC which improves the adhesion between resist and sample. The process parameter have been summarized in Sec. 3.6.1

- the ARC is followed by a layer of positive photo resist ("SPR 220-3").

- a resist thickness of $\approx 3.1 \mu \mathrm{m}$ has been chosen, because it supplies enough resist for the etch processes as well as good coverage of all topographical steps. The process parameter are summarized below:

Resist layer 2: SPR-220 3

Spin speed: $\quad \approx 10.5 \mathrm{rad} / \mathrm{s}(\approx 100 \mathrm{rpm})$ for $\approx 5 \mathrm{~s} / \approx 157 \mathrm{rad} / \mathrm{s}(\approx 1500 \mathrm{rpm})$ for $\approx 40 \mathrm{~s}$

Soft bake: $\quad \approx 115^{\circ} \mathrm{C}$ for $\approx 90 \mathrm{~s}$

- the wafer is exposed with $200 \mathrm{~mJ} / \mathrm{cm}^{2}$, a focus of $1 \mu \mathrm{m}$, a numerical aperture of 0.48 , and a sigma of 0.5 in the "conventional" illumination mode

- the resist is treated with a post exposure bake, of $\approx 110^{\circ} \mathrm{C}$ for $\approx 60 \mathrm{~s}$, to improve the result of the lithography process.

- in the following, the structure is developed in "AZ 300 MIF" for $\approx 60 \mathrm{~s}$ followed by a DIW rinse and dried with nitrogen

- subsequently the wafer is exposed with UV light $\left(\approx 300 \mathrm{~kJ} / \mathrm{cm}^{2}\right)$ at a temperature of $\approx 90{ }^{\circ} \mathrm{C}$. This crosslinks the resist and lowers the etch rate in dry etch significantly.

\subsubsection{Pattern Transfer}

- the transfer process starts with a descum to remove the ARC at the bottom of the lithographically defined structures

- the used oxygen plasma etch does only remove the organic part of the ARC the inorganic part will be removed in the following etch based on fluoroform $\left(\mathrm{CHF}_{3}\right)$ chemistry. 
- the etch step with fluoroform chemistry is used to etch through the LTO cladding layer, the silicon device layer, the buried oxide layer, and a few $\mathrm{nm}$ into the silicon handle wafer (Fig. $6 \mathrm{~d}$ )).

- the process parameters are summarized in the table below, the etch is performed in a parallel pate reactive ion etcher:

\begin{tabular}{|c|c|}
\hline \multicolumn{2}{|l|}{ Descum } \\
\hline Tool: & RIE Unaxis 790 \\
\hline Time: & $\approx 7 \mathrm{~min}$ \\
\hline Gases: & $\mathrm{O}_{2} / \mathrm{Ar}$ \\
\hline Flow rates: & $\approx 5 \mathrm{ml} / \mathrm{min}(\approx 5 \mathrm{sccm}) / \approx 20 \mathrm{ml} / \mathrm{min}(\approx 20 \mathrm{sccm})$ \\
\hline Pressure: & $\approx 4 \mathrm{~Pa}(\approx 30 \mathrm{mTorr})$ \\
\hline RF power: & $\approx 50 \mathrm{~W}$ \\
\hline Ref. RF power: & $\approx 0 \mathrm{~W}$ \\
\hline \multicolumn{2}{|l|}{$\mathrm{SiO}_{2}$} \\
\hline Depth: & until the silicon handle wafer is reached \\
\hline Gases: & $\mathrm{O}_{2} / \mathrm{CHF}_{3}$ \\
\hline Flow rates: & $\approx 5 \mathrm{ml} / \mathrm{min}(\approx 5 \mathrm{sccm}) / \approx 45 \mathrm{ml} / \mathrm{min}(\approx 45 \mathrm{sccm})$ \\
\hline Pressure: & $\approx 6.7 \mathrm{~Pa}(\approx 50$ mTorr $)$ \\
\hline RF power: & $\approx 200 \mathrm{~W}$ \\
\hline Ref. RF power: & $\approx 0 \mathrm{~W}$ \\
\hline DC Bias: & $\approx 516 \mathrm{~V}$ \\
\hline Etch rate: & $\approx 35 \mathrm{~nm} / \mathrm{min}\left(\mathrm{SiO}_{2}\right) / \approx 20 \mathrm{~nm} / \mathrm{min}(\mathrm{Si})$ \\
\hline
\end{tabular}

\subsubsection{Cleaning}

- the wafers are cleaned with a combination of solvents and acids to remove the plasma baked resist after the etching as well as the ARC. Followed by an RCA clean and a BOE etch to complete the thinning process as well as the formation of the anchor holes.

- the first step of the cleaning is using a solution based on N-Methyl-2-pyrrolidone (Resist remover 1165 ) at $\approx 70{ }^{\circ} \mathrm{C}$ for $\approx 15$ min finished with a dump rinse

- the next step is an acid clean with piranha solution $\left(\mathrm{H}_{2} \mathrm{SO}_{4}: \mathrm{H}_{2} \mathrm{O}_{2}\right)$. The solution is used in a ratio of $\mathrm{H}_{2} \mathrm{SO}_{4}: \mathrm{H}_{2} \mathrm{O}_{2}$ (3:1) for $\approx 10$ min, followed by a dump rinse

- the last step is a solvent clean to remove the inorganic residuals of the ARC. The recommended stripper for "AZ BARLi-II" is "AZ 300T stripper", which is used at $\approx 80^{\circ} \mathrm{C}$ for $\approx 10 \mathrm{~min}$, followed by a dry rinse and spin dry

- subsequently an RCA clean as described earlier (3.1.5) is performed

- the RCA clean is followed by a wet oxide etch to complete the thinning process as well as the formation of the anchor holes. Diluted buffered hydrofluoric acid (BOE 6:1) is used for this etch, because this acid smoothes the oxide step but does not attack the interfaces between silicon and silicon dioxide, as would be attacked by diluted hydrofluoric acid.

- the sample is exposed to the diluted BOE (6:1) for $\approx 1$ min and $30 \mathrm{~s}$ to remove $\approx 200 \mathrm{~nm}$ of silicon dioxide (Fig. 6 e)), followed by a dump rinse and dry. 


\subsubsection{Deposition of Silicon Nitride}

- Low stress silicon nitride is used as the mechanical material, because it has high etch resistivity against hydrofluoric acid and potassium hydroxide.

- the final thickness of the silicon nitride layer is $\approx 400 \mathrm{~nm}$ with the net tensile stress of $\approx 300 \mathrm{MPa}$ (Fig. $6 \mathrm{f})$ )

- the deposition is performed at $\approx 850^{\circ} \mathrm{C}$

- the wafer boat is filled with dummy wafers and one clean bare silicon wafer on both sides of the SOI wafer to aid in uniformity

\subsection{Electrodes and Wire Bond Pads}

The metal lines and wire bond pads, to connect the cantilever chip to a printed circuit board (PCB), are created in a metal lift off process. The process is based on "Lift-off" resist in combination with a positive photoresist. Chromium and Gold $(\mathrm{Cr} / \mathrm{Au})$ are used as metals $[38,39]$. The $\mathrm{Cr}$ functions as an adhesion layer for the $\mathrm{Au}$. This combination is not attacked by the $\mathrm{HF}$ and $\mathrm{KOH}$, and is stable to temperatures of up to $350{ }^{\circ} \mathrm{C}$. A stack of three resist layers is used for the "Lift-off" process. The first layer is the ARC, followed by a layer of "Lift-off" resist, and finalized by a layer of positive photo resist. "Lift-off" resist is usually based on the solvent 1-methoxy-2-propanol to avoid mixing with the positive photoresist, which is usually based on anisole as solvent. "Lift-off" resist is not photo sensitive and therefore it is non-selectively dissolved by the developer, which creates an undercut of the photoresist layer. This undercut can be tuned with the soft bake temperature and time and is very important for a clean and reproducible "lift-off" process. After the lithography process, the sample has to be treated with an descum process and a short etch based on fluoroform chemistry, to remove the ARC at the bottom of the lithographically defined structures, to expose the silicon nitride below. The short dry etch also etches into the silicon nitride which further improves the adhesion of the metal to the silicon nitride.

\subsubsection{Lithography}

- the resist stack starts with an ARC prepared with the same parameter as in Sec. 3.6.1

- the second layer consist out of the "Lift-off" resist ("LOR 3A")

- followed by a layer of positive photoresist

- all parameter for the preparation of these three layers are summarized in table below: 
Resist

Resist layer 1: Barli II

Spin speed:

$\approx 10.5 \mathrm{rad} / \mathrm{s}(\approx 100 \mathrm{rpm})$ for $\approx 5 \mathrm{~s} / \approx 209.4 \mathrm{rad} / \mathrm{s}(\approx 2000 \mathrm{rpm})$ for $\approx 40 \mathrm{~s}$

Soft bake:

$\approx 200^{\circ} \mathrm{C}$ for $\approx 60 \mathrm{~s}$

Typ. thickness:

$\approx 180 \mathrm{~nm}$

Resist layer 2: LOR 3A

Spin speed:

Soft bake:

Typ. thickness:

$\approx 10.5 \mathrm{rad} / \mathrm{s}(\approx 100 \mathrm{rpm})$ for $\approx 5 \mathrm{~s} / \approx 314 \mathrm{rad} / \mathrm{s}(\approx 3000 \mathrm{rpm})$ for $\approx 40 \mathrm{~s}$

$\approx 210^{\circ} \mathrm{C}$ for $\approx 20 \mathrm{~min}$

$\approx 300 \mathrm{~nm}$

Resist layer 3: SPR-220 3

Spin speed:

Soft bake:

$\approx 10.5 \mathrm{rad} / \mathrm{s}(\approx 100 \mathrm{rpm})$ for $\approx 5 \mathrm{~s} / \approx 314 \mathrm{rad} / \mathrm{s}(\approx 3000 \mathrm{rpm})$ for $\approx 40 \mathrm{~s}$

$\approx 115^{\circ} \mathrm{C}$ for $\approx 90 \mathrm{~s}$

Typ. thickness:

$\approx 1200 \mathrm{~nm}$

- the wafer is exposed with two different doses to clear the deep anchor hole and avoid overdosing the other structures

- the first exposure is for all metal lines. This exposure uses $160 \mathrm{~mJ} / \mathrm{cm}^{2}$, a focus of $0.2 \mu \mathrm{m}$, a numerical aperture of 0.48 , and a sigma of 0.5 in the "conventional" illumination mode.

- the second exposure is for all anchor holes and deep trenches. This exposure uses $200 \mathrm{~mJ} / \mathrm{cm}^{2}$, a focus of $0.6 \mu \mathrm{m}$, a numerical aperture of 0.48 , and a sigma of 0.5 in the "conventional" illumination mode.

- the resist is treated with a post exposure bake, of $\approx 110^{\circ} \mathrm{C}$ for $\approx 60 \mathrm{~s}$

- in the following, the structure is developed in "AZ 300 MIF" for $\approx 60$ s followed by a DIW rinse and nitrogen dry

\subsubsection{Descum and Removal of ARC}

- the transfer process starts with a descum to remove the ARC at the bottom of the lithographically defined structures.

- the etch step with fluoroform chemistry is used to remove the residual of the ARC and to etch into the first few nanometer of the silicon nitride layer for an improvement of the adhesion between the metal and the silicon nitride layer.

- the process parameters are summarized in the table below, the etch is performed in a parallel pate reactive ion etcher: 


$\begin{array}{ll}\text { Descum } & \text { RIE Unaxis } 790 \\ \text { Tool: } & \approx 7 \mathrm{~min} \\ \text { Time: } & \mathrm{O}_{2} / \mathrm{Ar} \\ \text { Gases: } & \approx 5 \mathrm{ml} / \mathrm{min}(\approx 5 \mathrm{sccm}) / \approx 20 \mathrm{ml} / \mathrm{min}(\approx 20 \mathrm{sccm}) \\ \text { Flow rates: } & \approx 4 \mathrm{~Pa}(\approx 30 \mathrm{mTorr}) \\ \text { Pressure: } & \approx 50 \mathrm{~W} \\ \text { RF power: } & \approx 0 \mathrm{~W} \\ \text { Ref. RF power: } & \\ \text { ARC + SiN } & \\ \text { Time: } & \approx 1 \mathrm{~min} \\ \text { Gases: } & \mathrm{O}_{2} / \mathrm{CHF} \\ \text { Flow rates: } & \approx 5 \mathrm{ml} / \mathrm{min}(\approx 5 \mathrm{sccm}) / \approx 45 \mathrm{ml} / \mathrm{min}(\approx 45 \mathrm{sccm}) \\ \text { Pressure: } & \approx 6.7 \mathrm{~Pa}(\approx 50 \mathrm{mTorr}) \\ \text { RF power: } & \approx 200 \mathrm{~W} \\ \text { Ref. RF power: } & \approx 0 \mathrm{~W} \\ \text { DC Bias: } & \approx 516 \mathrm{~V} \\ \text { Etch rate: } & \approx 35 \mathrm{~nm} / \mathrm{min}\end{array}$

\subsubsection{Metal Deposition}

- the metal is deposited via evaporation

- it is important for the adhesion of the metal layer to the silicon nitride that the descum is done shortly before the loading of the wafers. Furthermore, it is important that the Cr crucible is clean of any contamination.

- the $\mathrm{Cr}$ is deposited at a rate of $0.05 \mathrm{~nm} / \mathrm{s}$ until a final thickness of $10 \mathrm{~nm}$ is reached

- the Au is deposited at a rate of $0.25 \mathrm{~nm} / \mathrm{s}$ until a final thickness of $120 \mathrm{~nm}$ is reached

- the "Lift-off" process is completed by dissolving the resist mask with a solvent solution based on N-Methyl-2-pyrrolidone at $\approx 70{ }^{\circ} \mathrm{C}$ for $\approx 3 \mathrm{~h}$

- the ARC is removed with piranha solution and "AZ 300T" as described in Sec. 3.6.3

\subsection{Structuring of the Mechanical Member}

The mechanical member of the transducer is shaped out of the silicon nitride layer. The shape is defined with a positive photoresist mask. Furthermore, the metal layer serves as a hard mask to improve the overlay error in critical regions. The lithography is based on ARC and positive photoresist. A dry etch process is used to transfer the structure into the silicon nitride layer. The etch chemistry based on fluoroform creates an etch rate of $\approx 60 \mathrm{~nm} / \mathrm{min}$ for silicon nitride and $\approx 30 \mathrm{~nm} / \mathrm{min}$ for the silicon dioxide layer underneath. The silicon nitride layer is over etched to ensure a good pattern transfer across all topographical steps.

\subsubsection{Lithography}

- the resist layers are prepared as described in Sec. 3.6.1

- the resist is exposed with $190 \mathrm{~mJ} / \mathrm{cm}^{2}$, a focus of $0.4 \mu \mathrm{m}$, a numerical aperture of 0.48 , and a sigma of 0.5 in the "conventional" illumination mode 
- the resist is treated with a post exposure bake, of $\approx 110{ }^{\circ} \mathrm{C}$ for $\approx 60 \mathrm{~s}$

- in the following, the structure is developed in "AZ $300 \mathrm{MIF}$ " for $\approx 60 \mathrm{~s}$ followed by a DIW rinse and nitrogen dry

\subsubsection{Pattern Transfer}

- the pattern transfer starts with a descum step to remove the ARC at the bottom of the lithographically defined structures

- the etch step with fluoroform chemistry is used to remove the residual of the ARC and to etch through the silicon nitride layer into the silicon dioxide layer

- the process parameters are summarized in the table below, the etch is performed in a parallel pate reactive ion etcher:

\begin{tabular}{ll} 
Descum & RIE Unaxis 790 \\
\hline Tool: & $\approx 7 \mathrm{~min}$ \\
Time: & $\mathrm{O}_{2} / \mathrm{Ar}$ \\
Gases: & $\approx 5 \mathrm{ml} / \mathrm{min}(\approx 5 \mathrm{sccm}) / \approx 20 \mathrm{ml} / \mathrm{min}(\approx 20 \mathrm{sccm})$ \\
Flow rates: & $\approx 4 \mathrm{~Pa}(\approx 30 \mathrm{mTorr})$ \\
Pressure: & $\approx 50 \mathrm{~W}$ \\
RF power: & $\approx 0 \mathrm{~W}$ \\
Ref. RF power: & \\
& \\
ARC + $\mathrm{SiN}+\mathrm{SiO}_{2}$ & \\
\hline Time: & $\approx 1 \mathrm{~min}$ \\
Gases: & $\mathrm{O}_{2} / \mathrm{CHF} 3$ \\
Flow rates: & $\approx 5 \mathrm{ml} / \mathrm{min}(\approx 5 \mathrm{sccm}) / \approx 45 \mathrm{ml} / \mathrm{min}(\approx 45 \mathrm{sccm})$ \\
Pressure: & $\approx 6.7 \mathrm{~Pa}(\approx 50 \mathrm{mTorr})$ \\
RF power: & $\approx 200 \mathrm{~W}$ \\
Ref. RF power: & $\approx 0 \mathrm{~W}$ \\
DC Bias: & $\approx 516 \mathrm{~V}$ \\
Etch rate: & $\approx 60 \mathrm{~nm} / \mathrm{min}(\mathrm{SiN}) / \approx 30 \mathrm{~nm} / \mathrm{min}\left(\mathrm{SiO}_{2}\right)$
\end{tabular}

\subsubsection{Cleaning}

- the sample is cleaned with piranha solution followed by "AZ 300K" as described in Sec. 3.6.3

\subsection{Hard Mask Preparation for Anisotropic Etching}

In the following step, a hafnium oxide (HfO) hard mask is deposited on the wafer sto protect the frontside, specifically the exposed areas of LTO, from potassium hydroxide (KOH)[40], which is used to etch V-grooves into the frontside of the wafer and to shape the backside of the cantilever chip. The quality of the HfO layer is very important to ensure proper protection of the frontside. The etch rate of $\mathrm{HfO}$ in $\mathrm{KOH}$ depends on the carbon content of the HfO layer. The carbon content originates from the organic molecule (tetrakis(ethylmethylamino)hafnium (TEMAH)) which is used in the atomic layer deposition (ALD) process. The content of carbon in the final layer can be lowered by the use of a plasma induced deposition and with an increase purge time, as well as purge flow rates. The HfO layer is later patterned with the openings for the $\mathrm{KOH}$ etch on the front- and backside of the wafer. The used process for the lithography and pattern transfer is very similar for both sides. The lithography is performed in a frontside and backside 
contact mask aligner lithography. The pattern is transferred with a sulfur hexafluoride chemistry into the $\mathrm{HfO}$ layer and a fluoroform chemistry for the transfer into the underlying $\mathrm{SiN} / \mathrm{SiO}_{2} / \mathrm{Si} / \mathrm{SiO}_{2}$ until the silicon handle wafer is reached.

For the reasons of ease of process and device development the actual work has been done on chips. We are describing it as wafers, because we see no reason why this could not have been done on full wafers in principle, for a fully batch fabricated process.

\subsubsection{Hafnium Oxide Deposition}

- the parameters chosen for the HfO deposition are summarized in the table below. The parameters are separated into the seven steps of the ALD process (surface cleaning, deposition, TEMAH dose, TEMAH purge, gas stabilization, $\mathrm{O}_{2}$ plasma, plasma purge). The final thickness of the ALD layer is $\approx 20 \mathrm{~nm}$, which provides enough protection against $\mathrm{KOH}$ and can encapsulate small contaminations on the wafer surface.

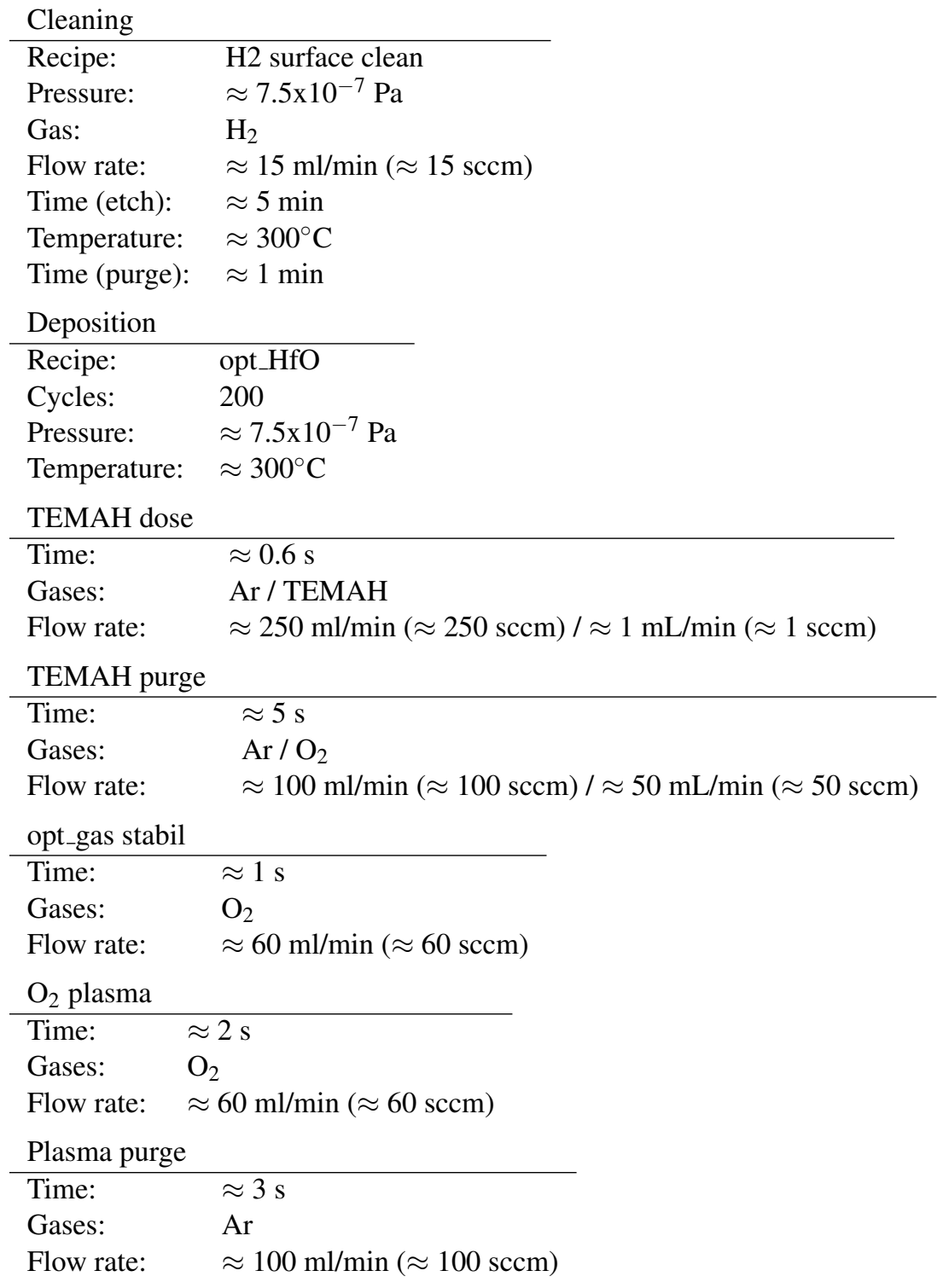




\subsubsection{Lithography}

- the wafer surface is prepared with hexamethyldiloxane as described in Sec. 3.2.1

- a thick positive photoresist is used to cover all topographical steps ("AZ 10xT")

- the resist is applied with a spin coater with a spin speed of $\approx 10.47 \mathrm{rad} / \mathrm{s}(\approx 100 \mathrm{rpm})$ for $\approx 5 \mathrm{~s}$ followed by $\approx 418.88 \mathrm{rad} / \mathrm{s}(\approx 4000 \mathrm{rpm})$ for $\approx 45 \mathrm{~s}$ to create a final resist thickness of $\approx 10 \mu \mathrm{m}$.

- the resist is soft baked $\approx 110{ }^{\circ} \mathrm{C}$ for $\approx 180 \mathrm{~s}$

- the wafer is exposed in a mask aligner lithography with a dose of $\approx 1000 \mathrm{~mJ} / \mathrm{cm}^{2}$

- the pattern is developed in diluted "AZ 400K" $(1: 3)$ for $\approx 180 \mathrm{~s}$ followed by a DIW rinse and dried with nitrogen

\subsubsection{Pattern Transfer}

- the pattern transfer starts with a sulfur hexafluoride chemistry to transfer the structure into the HfO layer

- this etch is followed by an etch based on fluoroform chemistry to transfer the structure into the underlying $\mathrm{SiN} / \mathrm{SiO}_{2} / \mathrm{Si} / \mathrm{SiO}_{2}$ until the silicon handle wafer is reached

- the process parameters are summarized in the table below, the etch is performed in a parallel pate reactive ion etcher:

\begin{tabular}{ll} 
HfO & \\
\hline Tool: & RIE Unaxis 790 \\
Time: & $\approx 5 \mathrm{~min}$ \\
Gases: & $\mathrm{SF}_{6} / \mathrm{CF}_{4}$ \\
Flow rates: & $\approx 6 \mathrm{ml} / \mathrm{min}(\approx 6 \mathrm{sccm}) / \approx 24 \mathrm{~mL} / \mathrm{min}(\approx 24 \mathrm{sccm})$ \\
Pressure: & $\approx 1 \mathrm{~Pa}(\approx 8 \mathrm{mTorr})$ \\
RF power: & $\approx 200 \mathrm{~W}$ \\
Ref. RF power: & $\approx 0 \mathrm{~W}$ \\
DC Bias: & $\approx 516 \mathrm{~V}$ \\
Etch rate: & $\approx 10 \mathrm{~nm} /$ min $(\mathrm{HfO})$ \\
$\mathrm{SiO}_{2} / \mathrm{SiN} / \mathrm{Si}$ & \\
\hline Tool: & $\mathrm{RIE} \mathrm{Unaxis} 790$ \\
Depth: & until the silicon handle wafer is exposed \\
Gases: & $\mathrm{O}_{2} / \mathrm{ChF} 3$ \\
Flow rates: & $\approx 5 \mathrm{ml} / \mathrm{min}(\approx 5 \mathrm{sccm}) / \approx 45 \mathrm{~mL} / \mathrm{min}(\approx 45 \mathrm{sccm})$ \\
Pressure: & $\approx 6.7 \mathrm{~Pa}(\approx 50 \mathrm{mTorr})$ \\
RF power: & $\approx 200 \mathrm{~W}$ \\
Ref. RF power: & $\approx 0 \mathrm{~W}$ \\
DC Bias: & $\approx 516 \mathrm{~V}$ \\
Etch rate: & $\approx 35 \mathrm{~nm} /$ min
\end{tabular}

\subsubsection{Backside Lithography and Pattern Transfer}

The process steps described in Secs. 3.9.2 and 3.9.3 have to be repeated on the backside of the wafer to define the openings for the backside anisotropic etching. The resist on the front side of the wafer is used as frontside protection during the backside lithography and pattern transfer process. 


\subsection{Bulk Micromachining}

This step defines the frontside V-grooves for the fiber attachment and it shapes the cantilever chip to make it compatible with commercial scanning probe microscopes. The anisotropic etching process is separated into two parts. In the first part, the front- and backside are etched simultaneously until the $\mathrm{V}$-grooves on the front side reach the final depth of $\approx 80 \mu \mathrm{m}$. At this point, the wafer is placed in a etch chuck to physically protect the frontside of the wafer from the etch solution and expose only the backside of the wafer. The backside is then etched until the backside etch reaches the frontside of the wafer and the membrane around the chip changes from a red, to an orange, and then to a clear color in the transmitted light. At this point, all the silicon on the membrane is gone and only the silicon dioxide membrane is left over.

\subsubsection{Cleaning}

- the photoresist on the front- and backside of the wafer is removed with N-Methyl-2-pyrrolidone at $\approx 110{ }^{\circ} \mathrm{C}$ for $\approx 15 \mathrm{~min}$

- followed by a dump rinse and spin dry

\subsubsection{Anisotropic Etching}

- the wafer is etched with a $30 \%$ solution of $\mathrm{KOH}$ in DIW at a temperature of $\approx 60{ }^{\circ} \mathrm{C}$

- the beaker should be covered to avoid a change in concentration due to evaporation

- both sides are etched until the final depth of $\approx 80 \mu \mathrm{m}$ for the frontside $\mathrm{V}$-grooves is reached

- at this point, the wafer is placed in a etch chuck to physically protect the frontside of the wafer from the etch solution and expose only the backside of the wafer

- the etch is continued at $\approx 80^{\circ} \mathrm{C}$ for $\approx 16 \mathrm{~h}$. Until the backside etch reaches the front side of the wafer and the membrane around the chip changes from a red, to an orange, and then to a clear color in the transmitted light. At this point, all the silicon on the membrane is gone and only the silicon dioxide membrane is left over.

- the wafer can be removed from the chuck and cleaned in warm DIW several times.

- followed by a clean in IPA and a carful drying with nitrogen

\subsection{Release}

The final release step consist out of an cleaning with $\mathrm{HCl}$ and DIW, followed by an $\mathrm{HF}$ sacrificial layer etch, which is completed with an intensive rinse with DIW. After the DIW rinse, the wafer is placed into several bathes of IPA to replace the DIW in all cavities with IPA. The wafer should stay in every bath for a couple of minutes. After all the DIW is replaced with IPA, the wafer is placed in an critical point dryer to critical point dry the released transducer. A study about the influence of the cleaning solutions and etch solutions used for the release and their influnece on the optical performance of the disk has been done by Borselli [41].

\subsubsection{Critical Point Drying}

- the release starts with a cleaning in $\mathrm{HCl}$ for $\approx 10$ min to remove residuals of $\mathrm{KOH}$

- followed by a dump rinse cycle until a sufficient bath resistivity is reached again 
- after the wafer is cleaned, the $\mathrm{HfO}$ protection layer and $\mathrm{SiO}_{2}$ sacrificial layer are etched in $\mathrm{HF}$ (49\%) until all mechanical structures are sufficiently undercut. The release etch for the described structure is $\approx 4$ min and $30 \mathrm{~s}$, which results in an undercut of $\approx 7 \mu \mathrm{m}$.

- the HF etch is followed by extensive dump rinse cycles to remove all HF residuals form the substrate

- in the following is the DIW replaced with IPA. This takes place in several bathes, each bath $\approx 10 \mathrm{~min}$

- before the sample is placed in the critical point dryer to dry the released transducers

\section{Conclusion}

This article has reported a comprehensive process for the batch fabrication of a fiber $f$ optomechanical transducer platform with overhanging cantilevers. Using this process we have fabricated a wide variety of transducers based on an optomechanical readout. The device presented in this work with the were designed "Nanolithography Toolbox", a free software package developed by the Center for Nanoscale Science and Technology $[42,43]$

\section{References}

[1] Srinivasan K, Miao H, Rakher MT, Davanço M, Aksyuk V (2011) Optomechanical Transduction of an Integrated Silicon Cantilever Probe Using a Microdisk Resonator. Nano Letters 11(2):791-797. https://doi.org/10.1021/nl104018r

[2] Regal CA, Teufel JD, Lehnert KW (2008) Measuring nanomechanical motion with a microwave cavity interferometer. Nature Physics : 1-7. https://doi.org/10.1038/nphys974

[3] Michels T, Rangelow IW (2014) Review of scanning probe micromachining and its applications within nanoscience. Microelectronic Engineering 126(C):191-203. https://doi.org/10.1016/j.mee.2014.02.011

[4] Michels T, Guliyev E, Klukowski M, Rangelow IW (2011) Micromachined self-actuated piezoresistive cantilever for high speed SPM. Journal of Microelectromechanical Systems:1-4. https://doi.org/10.1016/j.mee.2012.03.029

[5] Michels T, Aksyuk V (2016) Cavity Optical Transducer Platform with Integrated Actuation for Multiple Sensing Applications. Hilton Head 2016 Workshop, pp 1-5.

[6] Michels T, Rangelow IW, Aksyuk V (2016) Cantilever array with optomechanical read-out and integrated actuation for simultaneous high sensitivity force detection. In Proceedings of the International Conference on Optical MEMS and Nanophotonics, pp 1-2.

[7] Miao H, Srinivasan K, Rakher MT, Davanço M, Aksyuk V (2011) Cavity optomechanical sensors. In Proceedings of the 16th International Solid-State Sensors, Actuators and Microsystems Conference (TRANSDUCERS), pp 1-4. https://doi.org/10.1109/TRANSDUCERS.2011.5969730

[8] Zou J, et al. (2014) Integrated silicon optomechanical transducers and their application in atomic force microscopy. arXivorg 1405.3343v1.

[9] Grutter KE, Davanço M, Srinivasan K (2014) $\mathrm{Si}_{3} \mathrm{~N}_{4}$ nanobeam optomechanical crystals. arXivorg 1411.5996.

[10] Kippenberg TJ, Vahala KJ (2014) Cavity Opto-Mechanics. Optical Express 15(25):1-34. https://doi.org/10.1364/OE.15.017172

[11] Vahala K (2014) JMD3 - Cavity Opto-Mechanics. Technical report.

[12] Borselli M, Johnson TJ, Painter O (2005) Beyond the Rayleigh scattering limit in high-Q silicon microdisks: theory and experiment. Optics express 13(5):1515-1530. https://doi.org/10.1364/OPEX.13.001515

[13] Borselli M, Johnson TJ, Painter O (2006) Measuring the role of surface chemistry in silicon microphotonics. Applied Physics Letters 88(13):131114-3. https://doi.org/10.1063/1.2191475

[14] Forstner S, et al. (2012) Cavity Optomechanical Magnetometer. Physical Review Letters 108(12):120801-5. https://doi.org/10.1103/PhysRevLett.108.120801

[15] Robinson JT, Chen L, Lipson M (2008) On-chip gas detection in silicon optical microcavities. Optical Express :1-6. https://doi.org/10.1364/OE.16.004296

[16] Metcalfe M (2014) Applications of cavity optomechanics. Applied Physics Reviews 1(3):031105. https://doi.org/10.1063/1.4896029

[17] Huang JG, et al. (2015) All optomechanical signal modulation in photonic circuits. In Proceedings of the 16th International Solid-State Sensors, Actuators and Microsystems Conference (TRANSDUCERS), pp 1-4. https://doi.org/10.1109/TRANSDUCERS.2015.7181363

[18] Hwekyung K, et al. (2010) Fabrication of Butt-coupling-capable Optical Receiver Assemblies for Optical Interconnections. Journal of the Korean Physical Society 57(61):1589-5.

[19] Gröblacher S, Hill JT, Safavi-Naeini AH, Chan J, Painter O (2013) Highly efficient coupling from an optical fiber to a nanoscale silicon optomechanical cavity . Applied Physics Letters :1-4. https://doi.org/10.1063/1.4826924 
[20] Srinivasan K, Painter O (2007) Mode coupling and cavity-quantum-dot interactions in a fiber-coupled microdisk cavity. Physical Review A 75(2):023814. https://doi.org/10.1103/PhysRevA.75.023814

[21] Li H, Chen Y, Noh J, Tadesse S, Li M (1) Multichannel cavity optomechanics for all-optical amplification of radio frequency signals. Nature Communications 3:1091-6. https://doi.org/10.1038/ncomms2103

[22] Lin Q, Rosenberg J, Jiang X, Vahala KJ, Painter O (2009) Mechanical oscillation and cooling actuated by the optical gradient force :1-29. https://doi.org/10.1103/PhysRevLett.103.103601

[23] Teufel JD, Donner T, Castellanos-Beltran MA, Harlow JW, Lehnert KW (2009) Nanomechanical motion measured with an imprecision below that at the standard quantum limit. Nature Nanotechnology 4(1):820-823. https://doi.org/10.1038/nnano.2009.343

[24] Kippenberg TJ, Rokhsari H, Carmon T, Scherer A, Vahala KJ (2008) Analysis of radiation-pressure induced mechanical oscillation of an optical microcavity. Physical Review Letters :1-12. https://doi.org/10.1103/PhysRevLett.95.033901

[25] Carmon T, Yang L, Vahala KJ (2004) Dynamical thermal behavior and thermal self- stability of microcavities. Optical Express :1-9. https://doi.org/10.1364/OPEX.12.004742

[26] Kippenberg TJ, Schliesser A (2014) Cavity optomechanics with whispering-gallery mode optical micro-resonators . Physical Review $A$ :1-122.

[27] Faust T, et al. (2012) Nonadiabatic Dynamics of Two Strongly Coupled Nanomechanical Resonator Modes. Physical Review Letters 109:1-4. https://doi.org/10.1103/PhysRevLett.109.037205

[28] Unterreithmeier QP, Weig EM, Kotthaus JP (2009) Universal transduction scheme for nanomechanical systems based on dielectric forces. Nature 458(7241):1001-1004. https://doi.org/10.1038/nature07932

[29] Vina L, Cardona M (1984) Effect of heavy doping on the optical properties and the band structure of silicon. Physical Review B :1-13. https://doi.org/10.1103/PhysRevB.29.6739

[30] Kern W (1990) The Evolution of Silicon Wafer Cleaning Technology. J Electrochem Soc 137(6):1-6. https://doi.org/10.1149/1.2086825

[31] Mohammad M, et al. (2012) Study of Development Processes for ZEP-520 as a High-Resolution Positive and Negative Tone Electron Beam Lithography Resist. Japanese Journal of Applied Physics :1-9. https://doi.org/10.1143/JJAP.51.06FC05

[32] Ocola LE, Stein A (2006) Effect of cold development on improvement in electron-beam nanopatterning resolution and line roughness. J Vac Sci Technol 6(24):1-6. https://doi.org/10.1116/1.2366698

[33] Olynick DL, Liddle JA, Harteneck BD, Cabrini S, Rangelow IW (2007) Nanoscale pattern transfer for Templates, NEMs, and Nano-optics. SPIE, pp 1-8.

[34] Goodyear AL, Mackenzie S, Olynick DL, Anderson EH (2000) High resolution inductively coupled plasma etching of $30 \mathrm{~nm}$ lines and spaces in tungsten and silicon. $J$ Vac Sci Technol :1-5. https://doi.org/10.1116/1.1326922

[35] Shearn M, Sun X, Henry M, Yariv A, Scherer A (2012) Advanced Plasma Processing: Etching, Deposition, and Wafer Bonding Techniques for Semiconductor Applications.

[36] Wagner ML, Nine R (2013) The Use of HBr in Polysilicon Etching.

[37] Lis S, Dylewicz R, Mysliwiec J, Miniewicz A, Patela S (2008) Application of flowable oxides in photonics. Materials Science-Poland 26(1):1-6.

[38] Williams K, Muller S (1996) Etch Rates for Micromachining Processing. Journal of Microelectromechanical Systems 5(4):1-14. https://doi.org/10.1109/84.546406

[39] Williams K, Gupta K, Wasilik M (2003) Etch rates for micromachining processing-part II. Journal of Microelectromechanical Systems 12(6):1-18. https://doi.org/10.1109/JMEMS.2003.820936

[40] Tanaka H, Yamashita S, Abe Y, Shikida M, Sato K (2003) Fast Wet anisotropic Etching of Si100 and 110 with a Smooth Surface in Ultra-High Temperature KOH Solutions In Proceedings of the 12th International Conference on Solid-State Sensors, Actuators and Microsystems (TRANSDUCERS), pp 1-4. https://doi.org/10.1109/SENSOR.2003.1217105

[41] Borselli M (2016) High-Q Microresonators as Lasing Elements for Silicon Photonics. Ph.D. thesis California Institute of Technology.

[42] Ilic RR, et al. (2016) Nanolithography Toolbox (U.S. Department of Commerce, Washington, D.C.), NIST Handbook 160. https://doi.org/10.6028/NIST.HB.160

[43] Balram KC, et al. (2016) The Nanolithography Toolbox. Journal of Research of the National Institute of Standards and Technology 121:1-12. https://doi.org/10.6028/jres.121.024

About the authors: Thomas Michels is an attending PhD student of the Ilmenau University of Technology, Germany. He is a visiting guest researcher in the Nanofabrication group at the Center for Nanoscale Science and Technology at the National Institute of Standards and Technology (NIST). Ivo W. Rangelow is the head of the Department of Microelectronics and Nanoelectronics at the Ilmenau University of Technology, Germany. Vladimir Aksyuk is a Project Leader in the Nanofabrication research group at the Center for Nanoscale Science and Technology at (NIST). The National Institute of Standards and Technology is an agency of the U.S. Department of Commerce. 